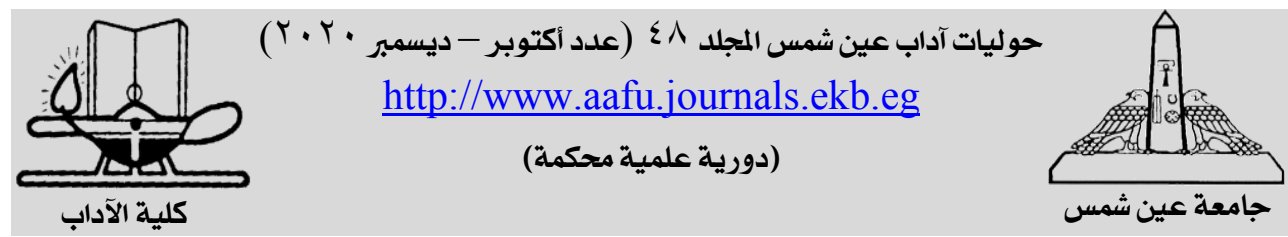

القزاءة الظاهر اتية للنص المسرحي

أ.م.د. سافرة ناجي جاسم

كلية الفنون الجميلة - جامعة بغداد

ترسم الظاهر اثية معطياتها الفلسفية بحسب طروحات (هوسرل) من خلال التوفيق ولات وليق

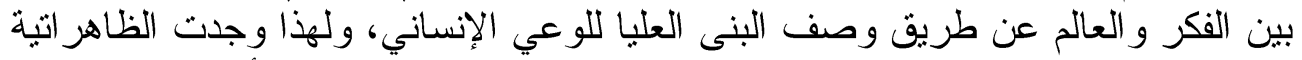

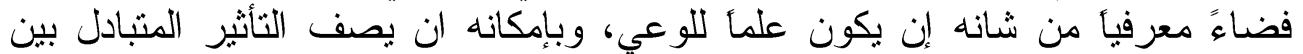

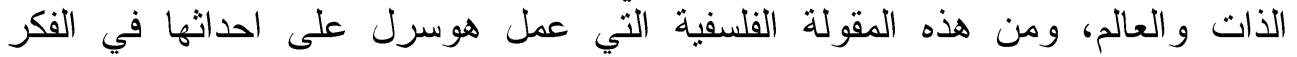

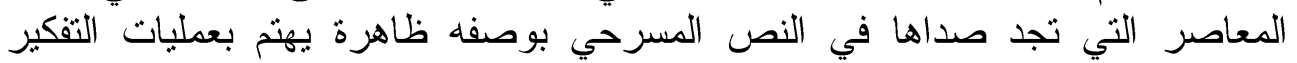

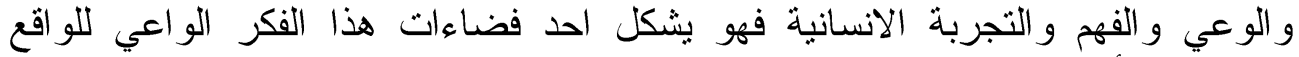

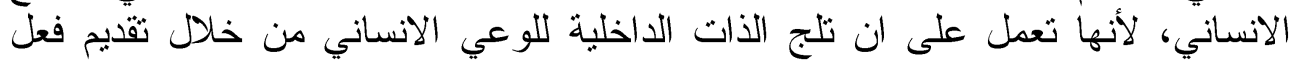

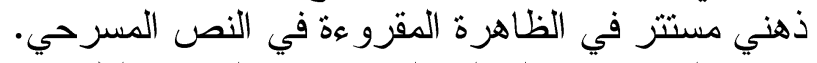

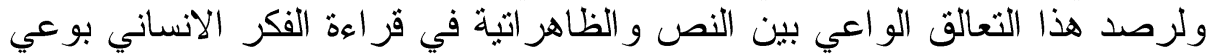

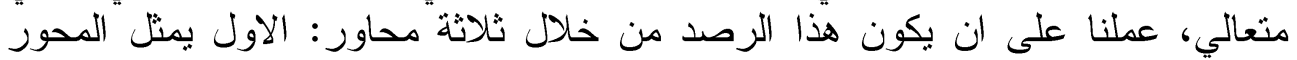

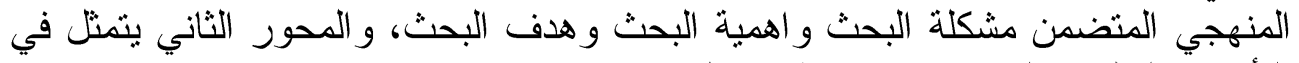
التأسيس النظري الذي تضمن ثلاثة مداخل هي:

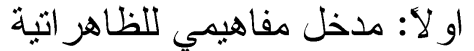
ثانيا: مرتكز ات الظأهر اتية النقدية

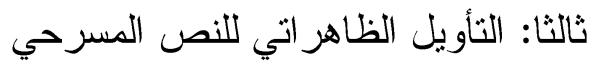

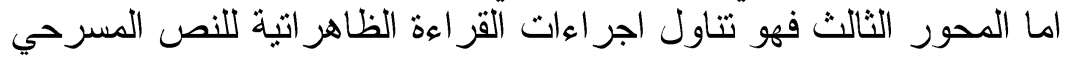

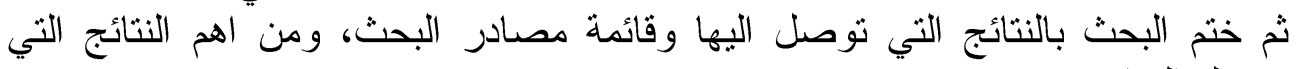

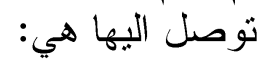

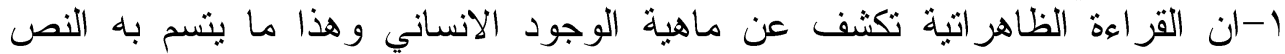

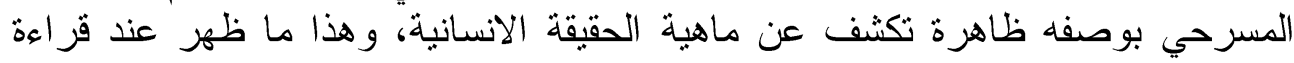

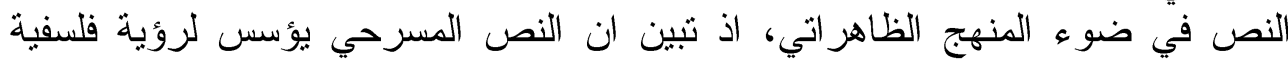

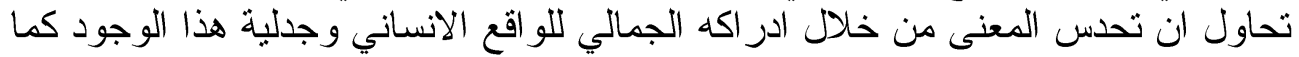

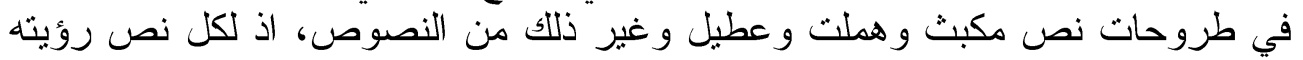
القلففية ذات الوعي القصدي. r- اظهرت تحليل عينة البحثث ان النص المسرحي هو الفضاء الذي يكثف عن حضور

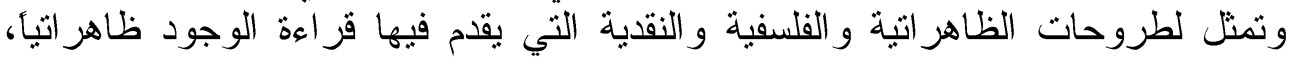

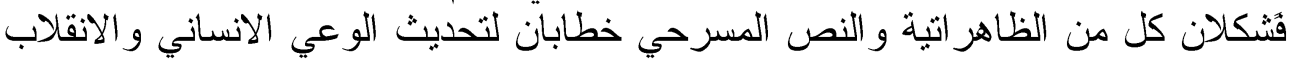

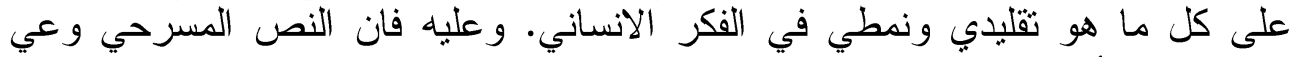

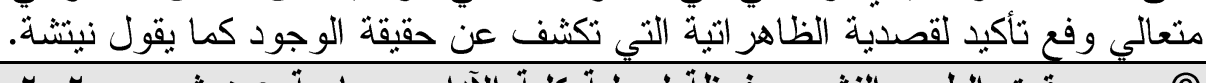

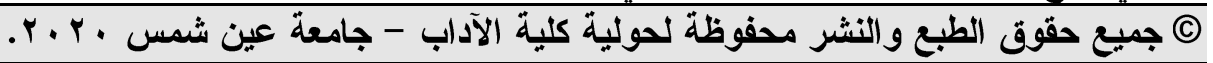




\section{المحور المنهجي}

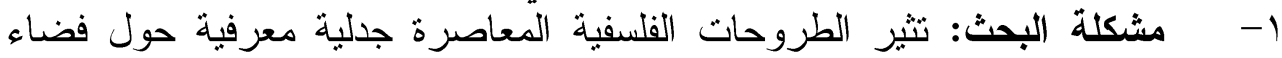

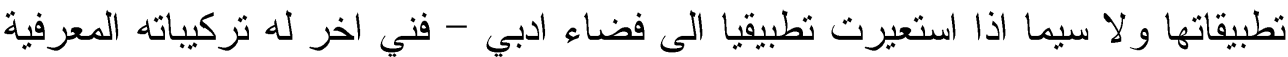

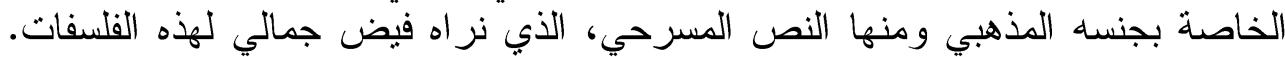
بوصفه تعبير عن الذات الانسانية التي تمثل فضاء تطبيقيا لكل الطروحات الفئية الفلسفية ومن

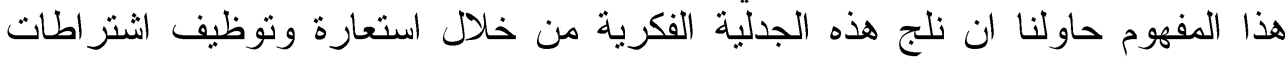

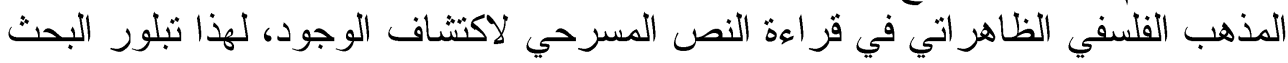
بعنو ان: ( القر أعة الظاهر اتية للنص النص المسرحي). r- الهية البحث: تتهيكل اهمية هذا البحث في تقديم دراسة جمالية تبين التذاخل

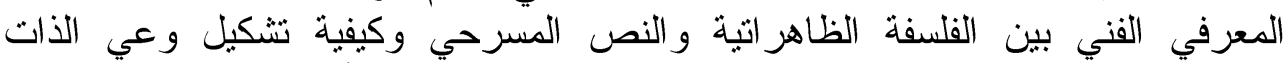
الانسانية ومنها الذات الفنية المدركة للواقع بوعي جمالي من شأنه ان بهرب الفي الوعي بعدا

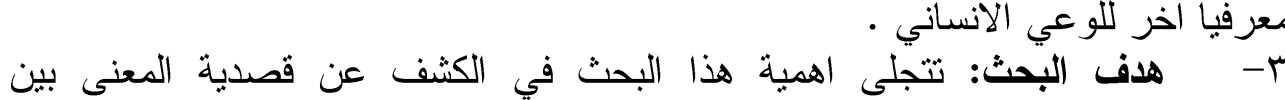
الظاهر اتبة و النص المسرحي.

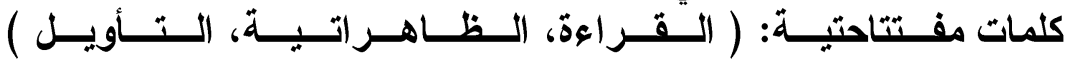


المحور (النظري

اولا-ـَ: مدخل مفاهيمي للظاهر اتية:

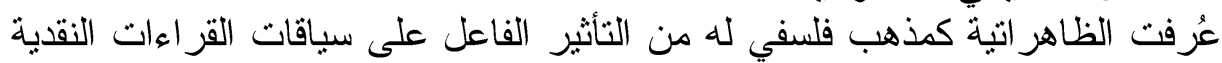

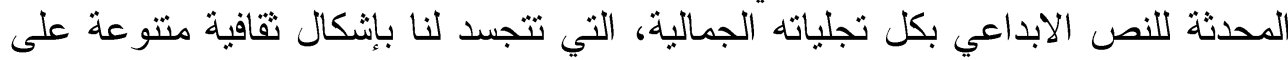

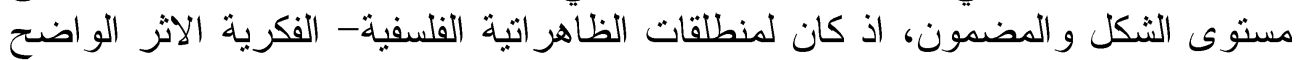

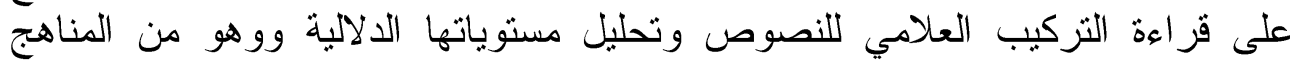

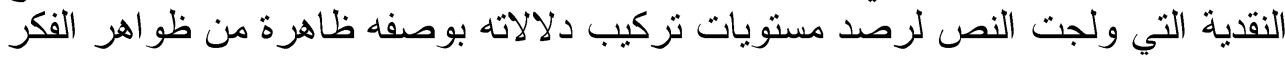

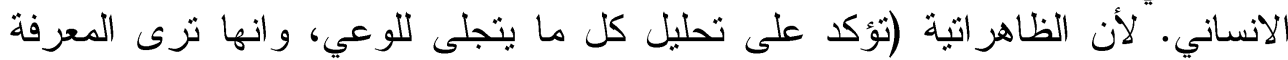

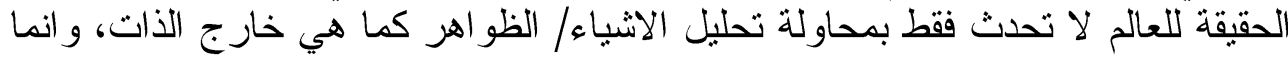

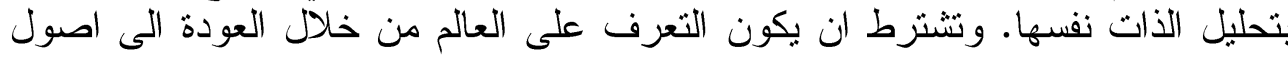

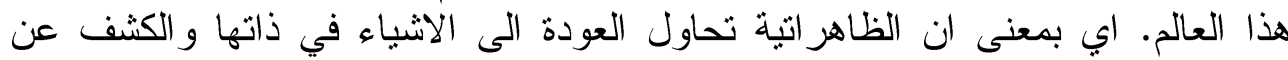

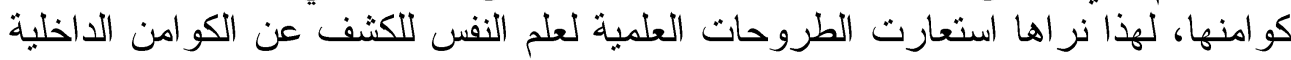

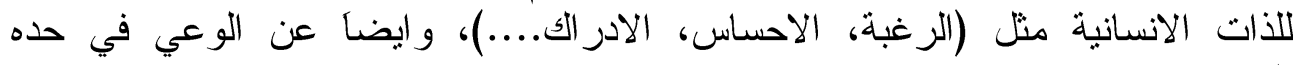
النفسي.

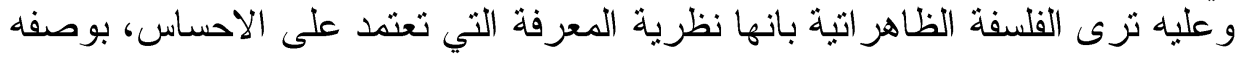

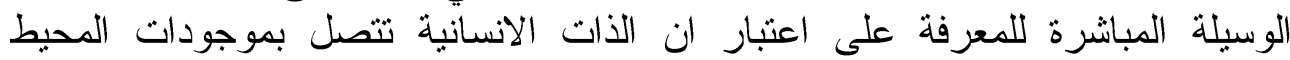

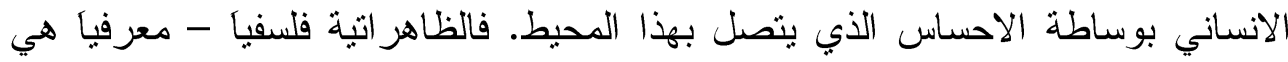

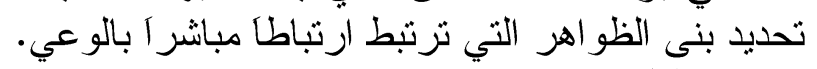

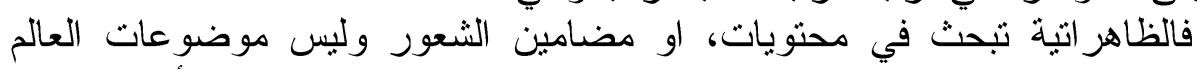

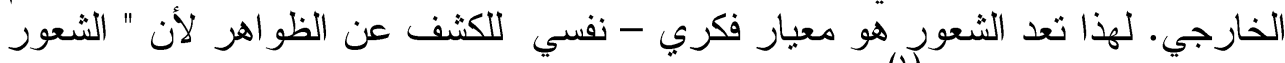

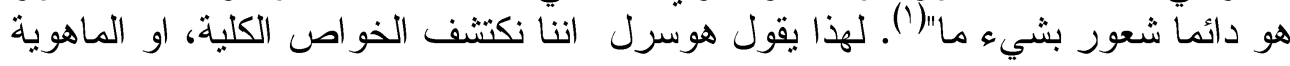

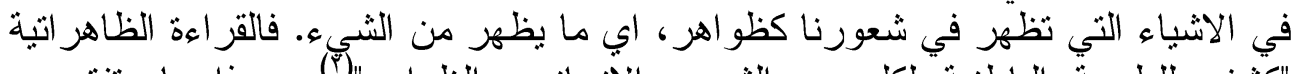

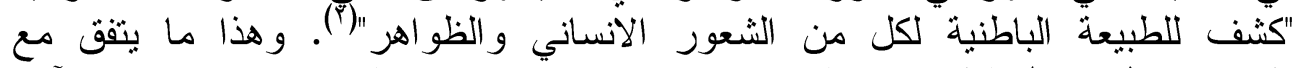

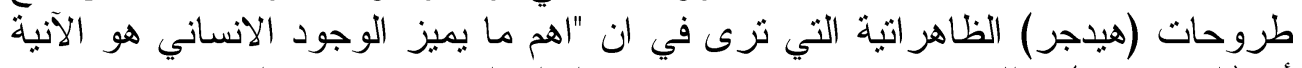

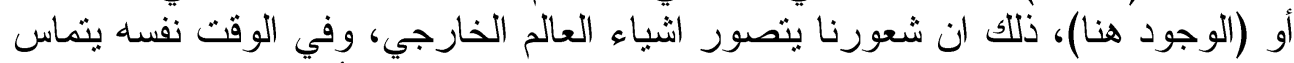

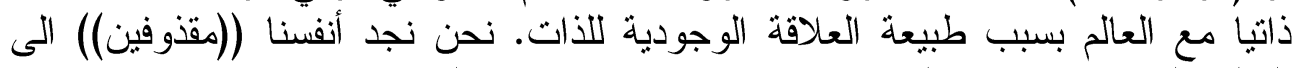

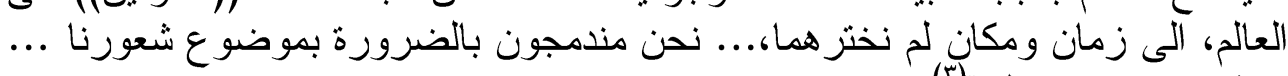

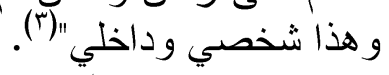

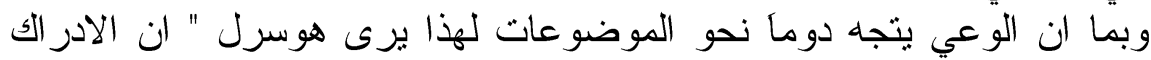

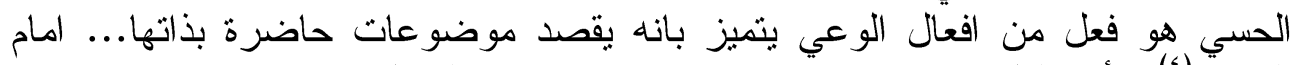

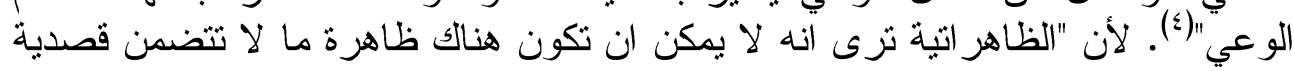

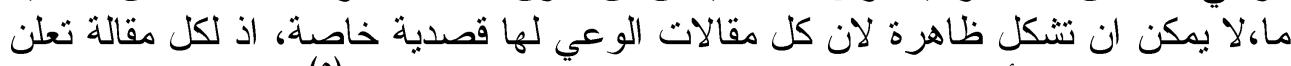

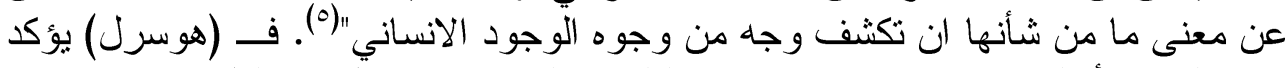

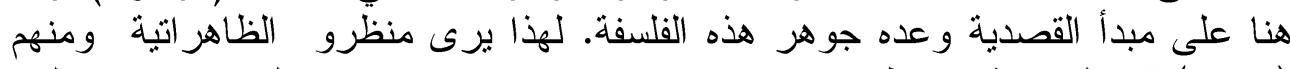

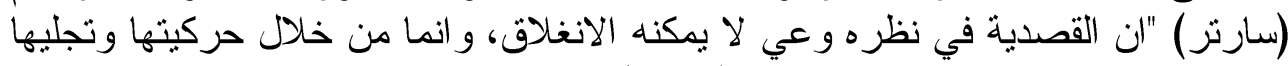

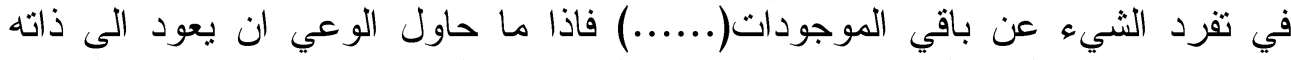

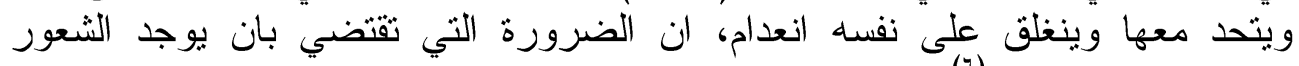

كشعور بشيء غيره" 
لذلك نجد ان الظاهر اتية وعي يقصد موضوع المعنى بوصفها حضور غائب، كما

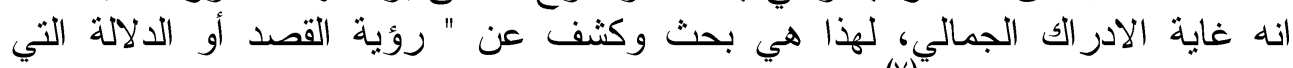

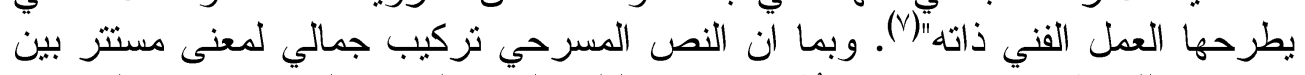

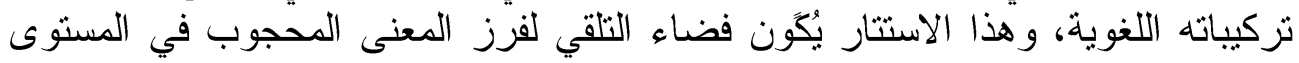

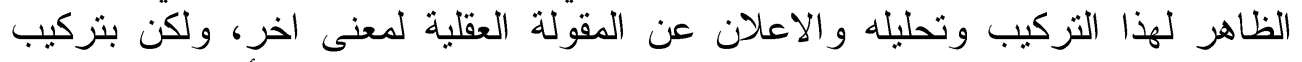

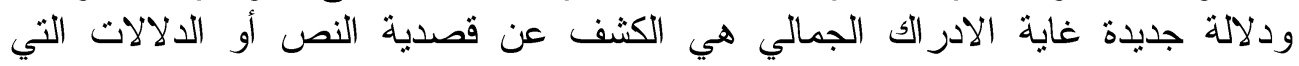
بطرحها العمل الفني ذاته.

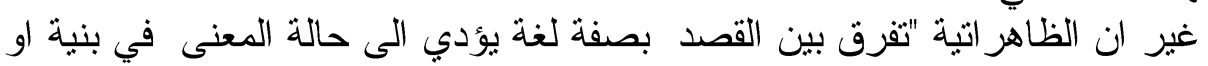

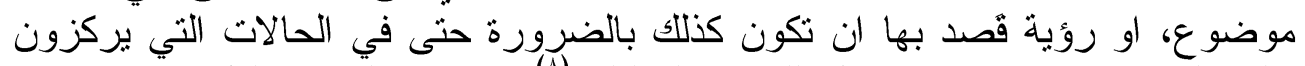

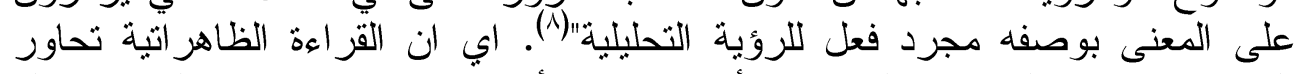

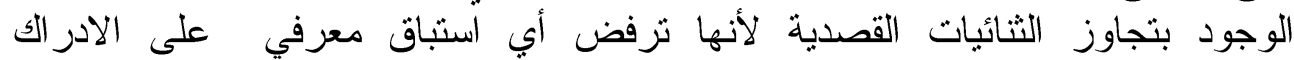

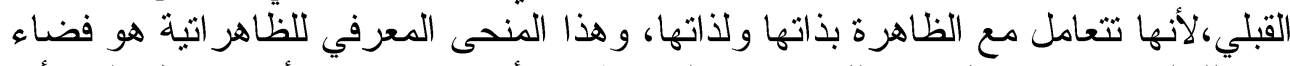

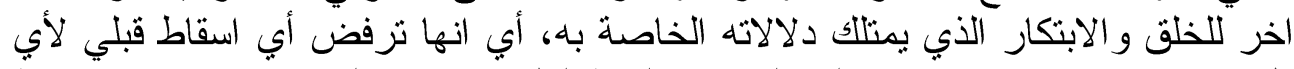

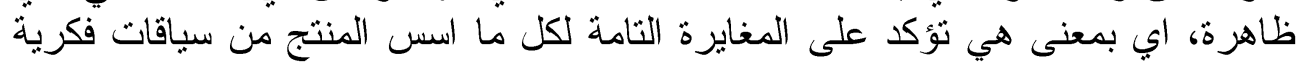

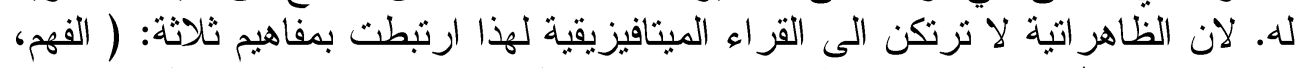

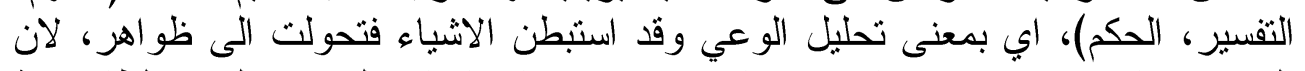

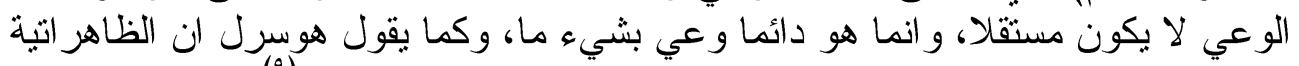

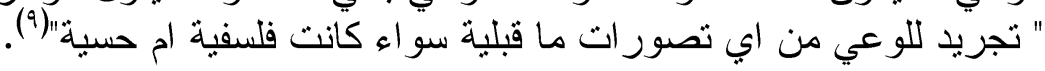

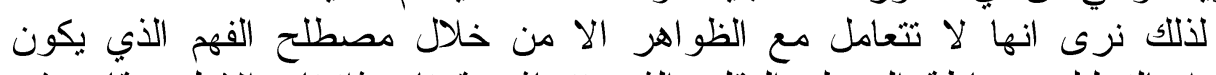

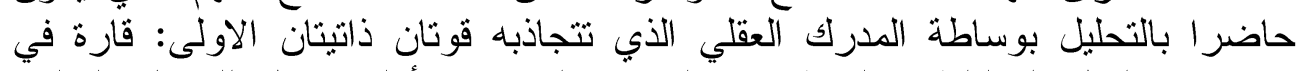

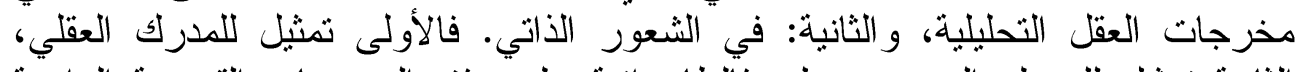

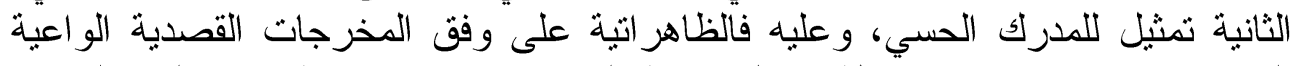

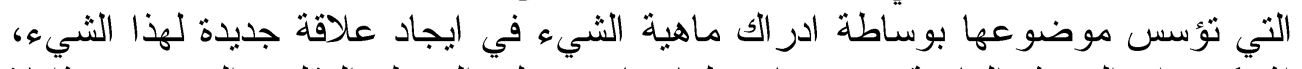

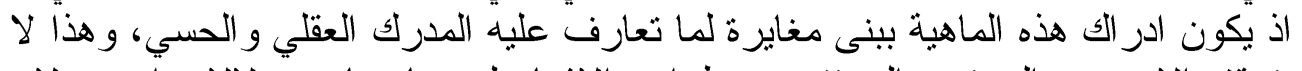

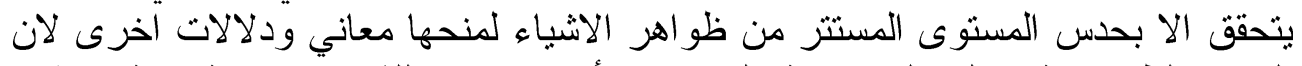

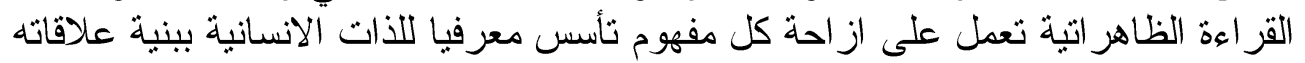

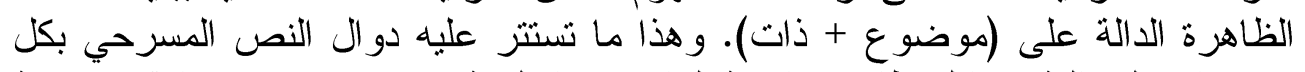

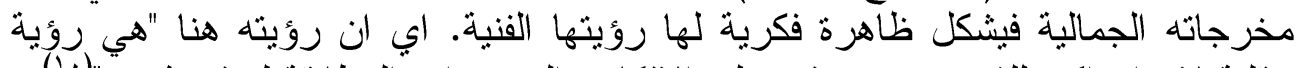

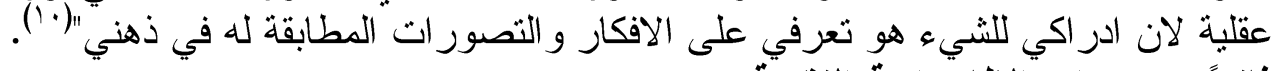
ثانياً: مرتكز ات ات الظاهز اتية النقدية:

تؤسس الظاهر انية قر اعتها النقدية للطبيعة واتهة الانسان بتفكيك (الوجود الانساني من

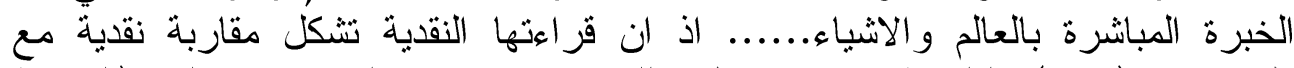
طروحات (كانت) الفلسفية في ملاحظته للوجود الانساني التي التي ردها التى الى (المعرفة

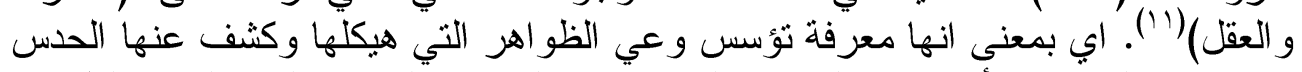

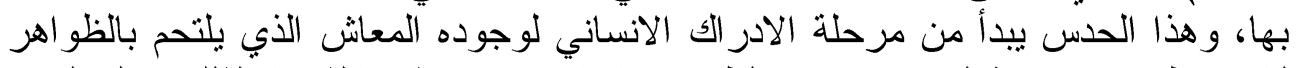

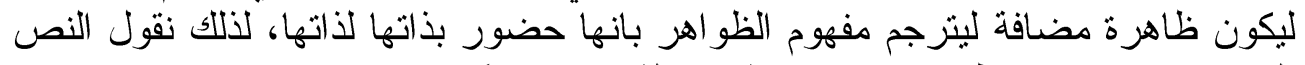

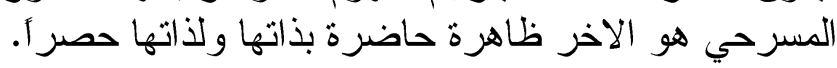

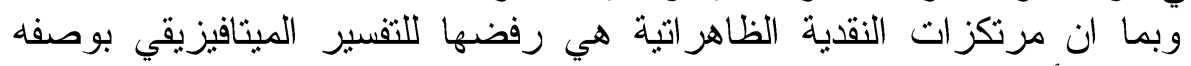

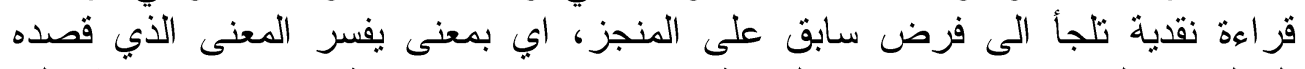

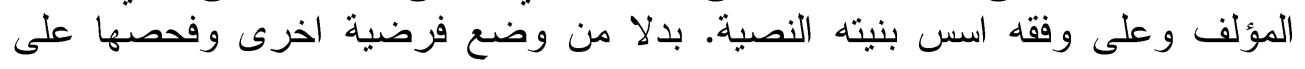




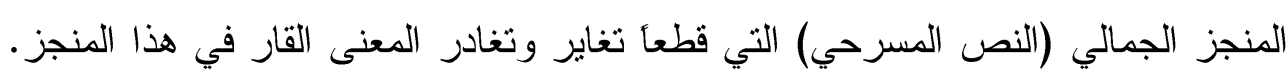

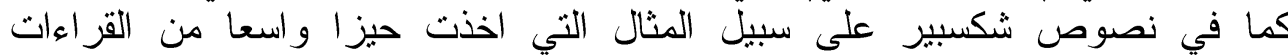

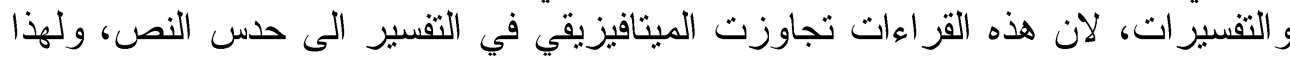

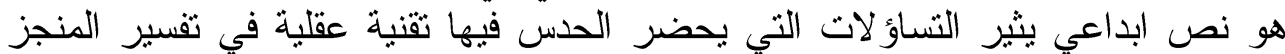

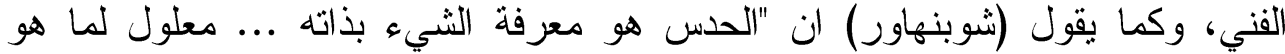

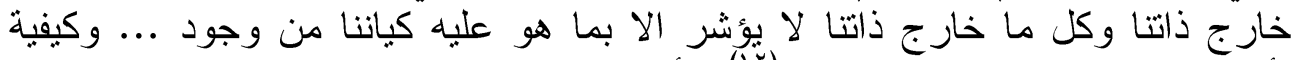

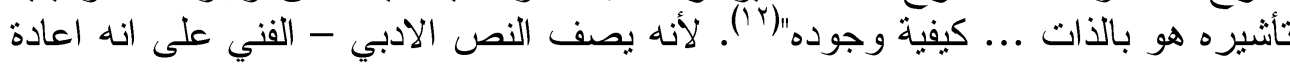

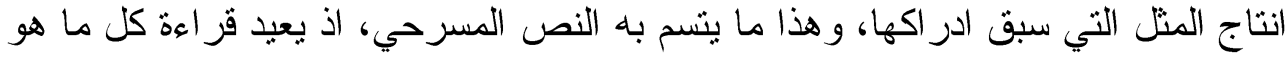

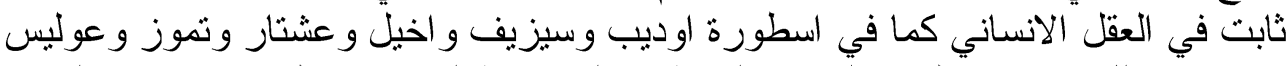

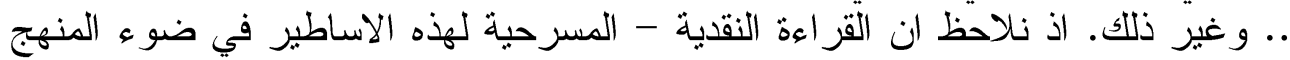

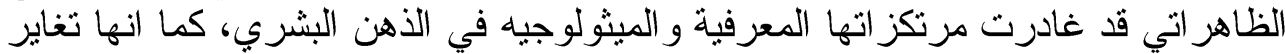

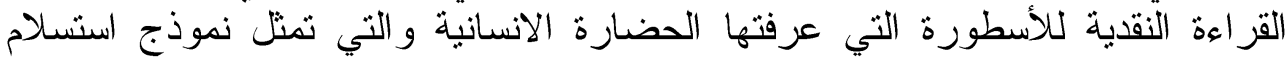

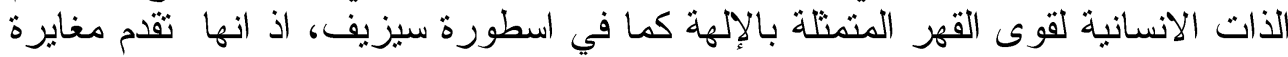

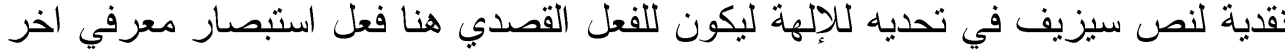

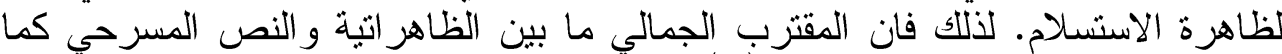

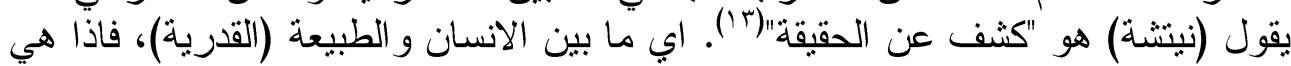

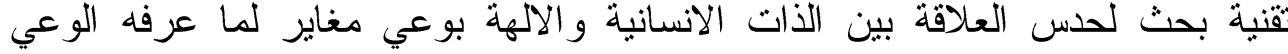

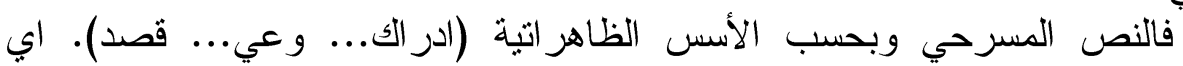
الانساني.

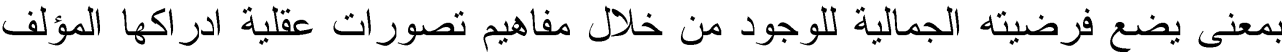

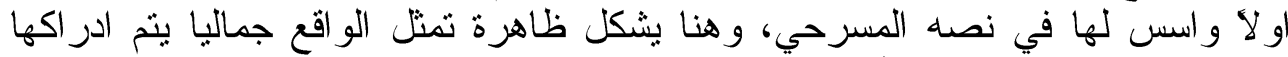

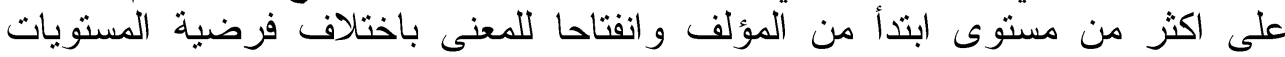

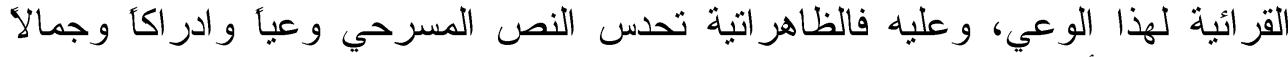

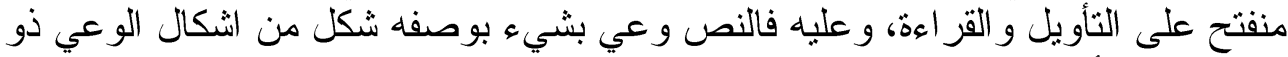

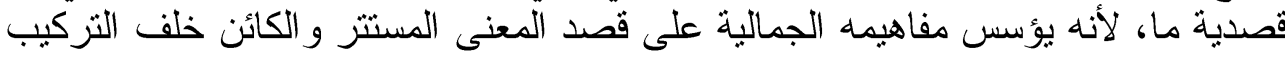
اللغوي و الفني ومن مرنكزات الظاهر اتية في مقاربتها النقدية للنص المسرحي في عملية

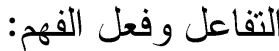

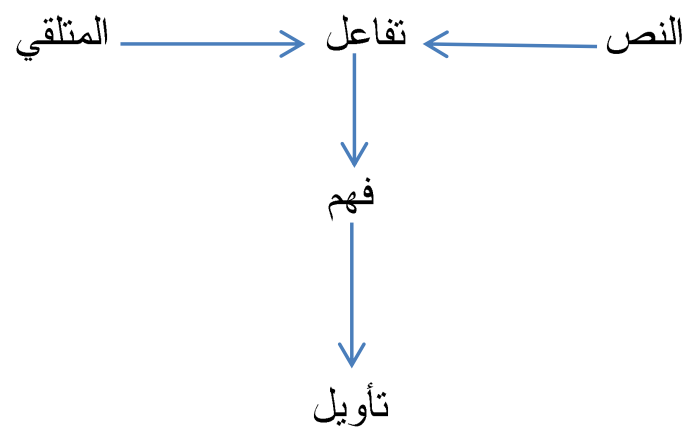

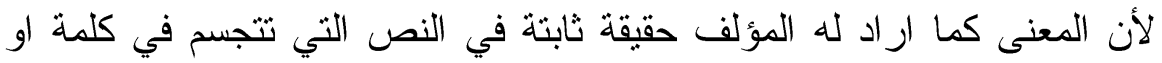

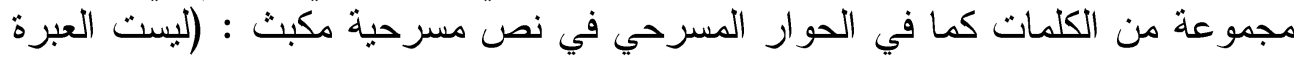
ان تكون ملكأ، بل العبرة ان تكون امنأ) فان الحوار هنا يشر الى انه "تجاوز لمعناها 
قصدا معينأ ويمكن ان يفهمها ويؤلها كل فرد يحسن نلك اللغة"(أ) اي ان اللغة تكتسب

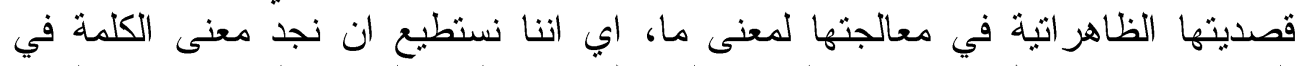

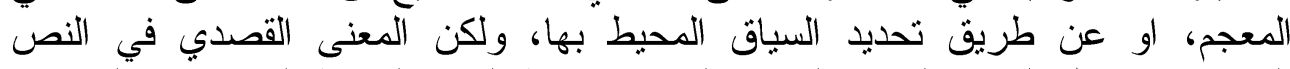

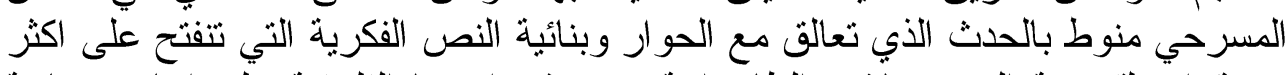

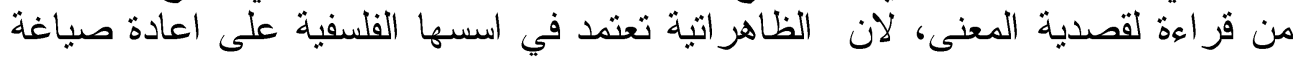

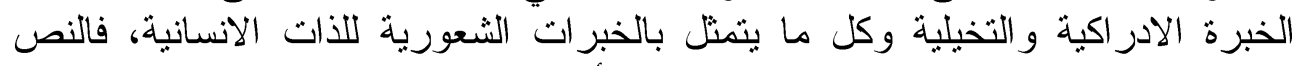

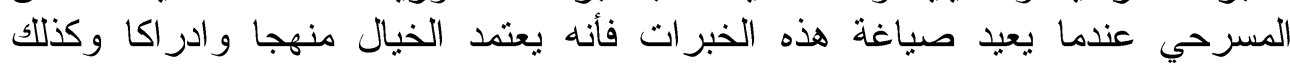

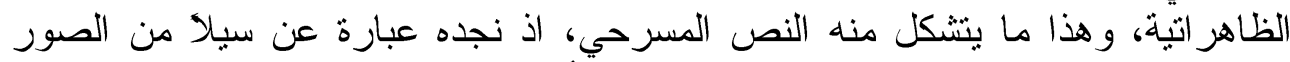

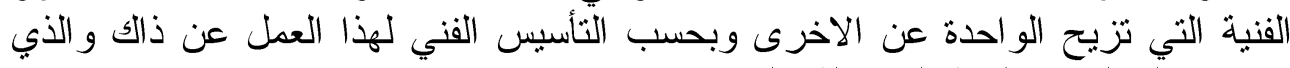

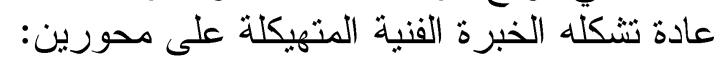

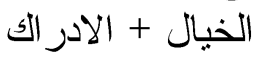

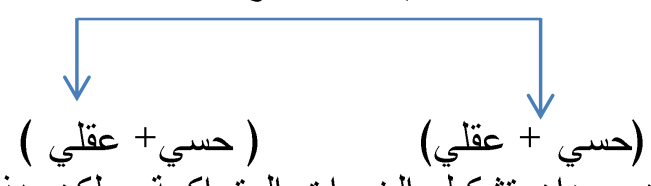

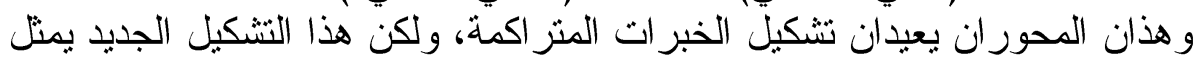

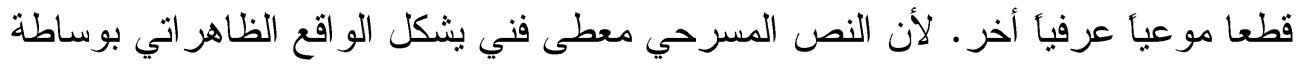

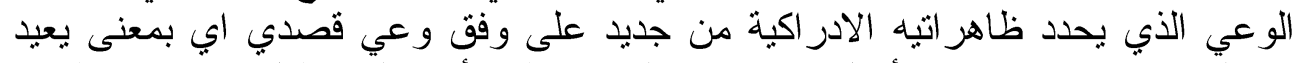

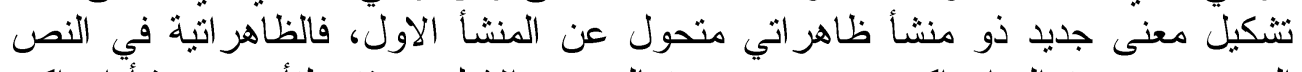

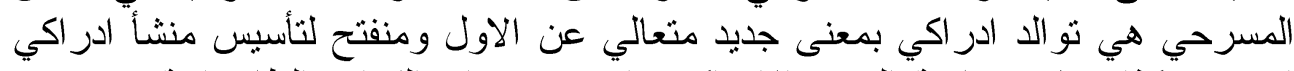

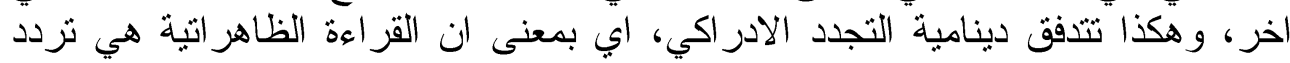

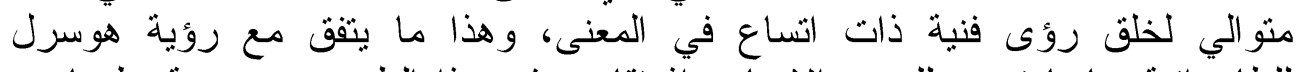

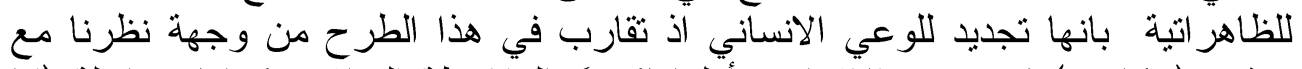

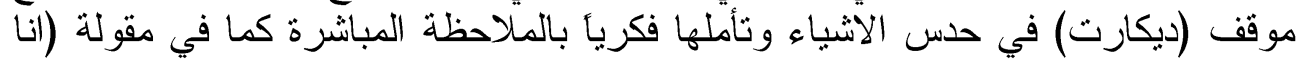

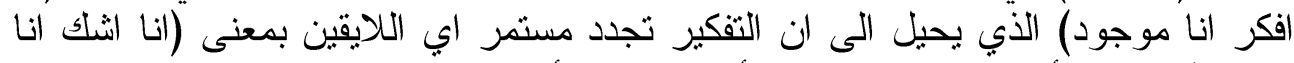

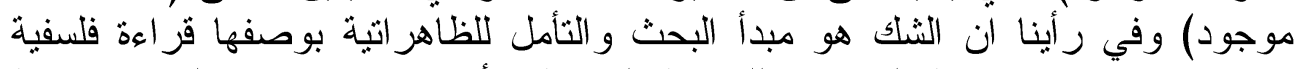

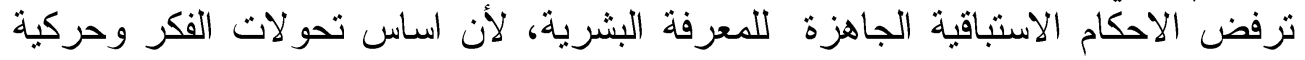

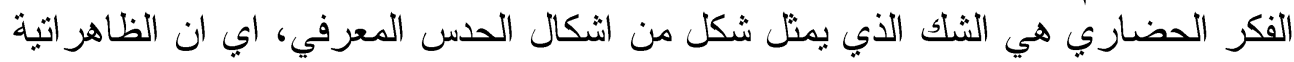

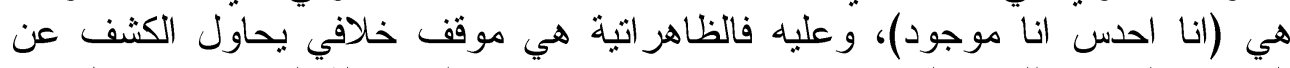

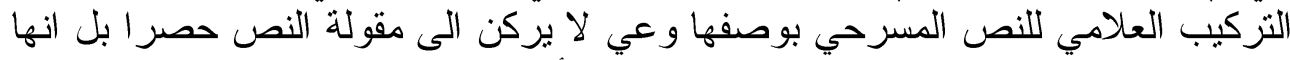

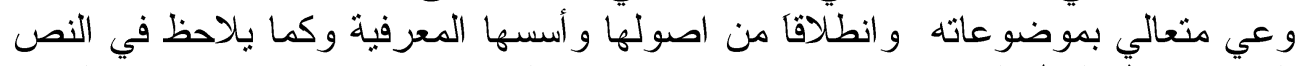

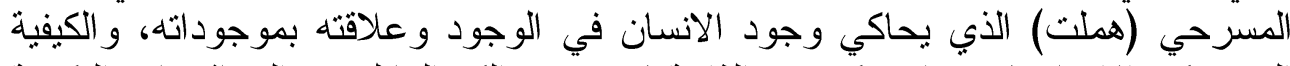

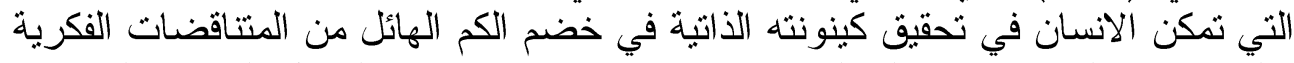

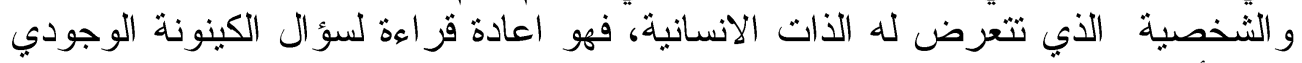

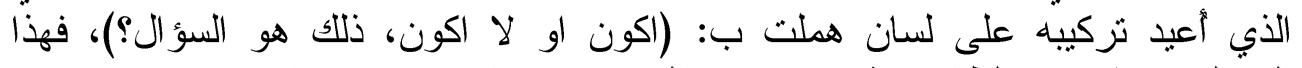

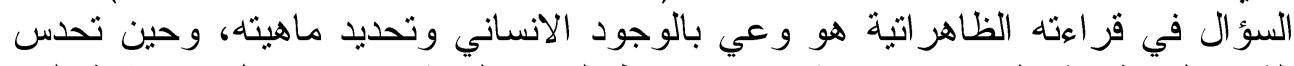

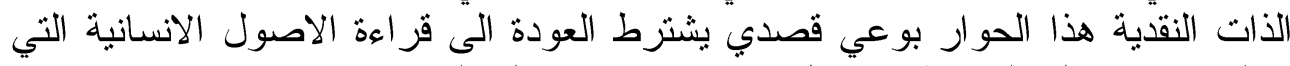

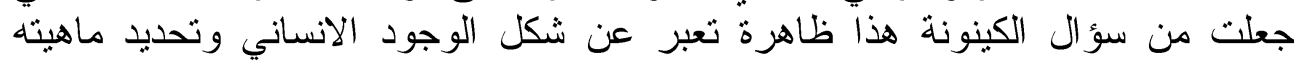

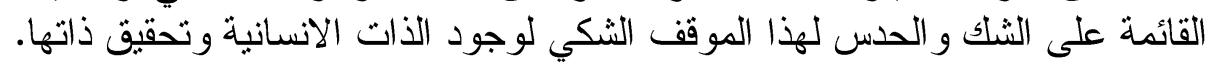

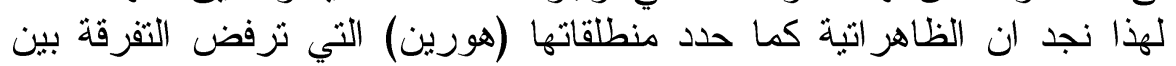

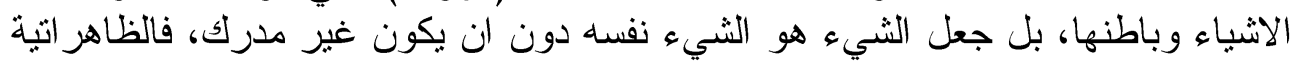


تهب معنى للاشياء وتؤسسها في الخبرة المباشرة اي لحظة التفاعل مع الظاهرة بشقيها

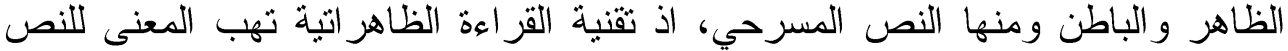

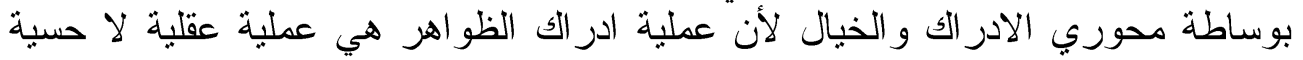
يكونها الذهن بحكم الوعي بوساطة الحس وصولان الإلى التى الادرالك الجمالي، وعليه

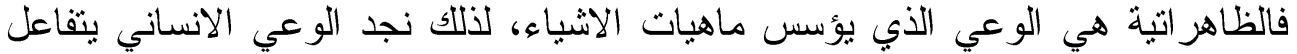

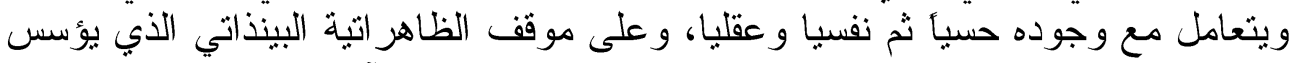

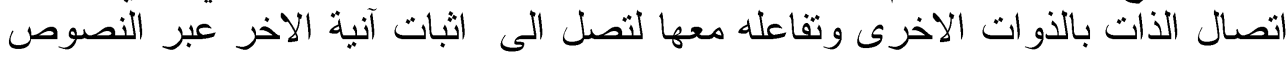

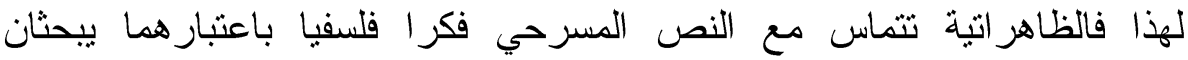
المسرحية.

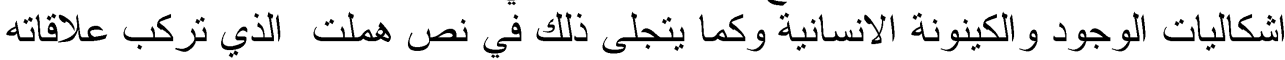

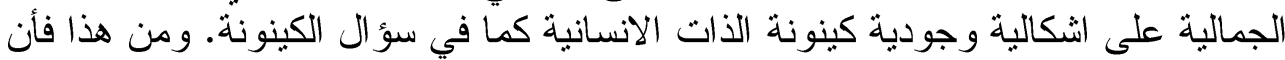

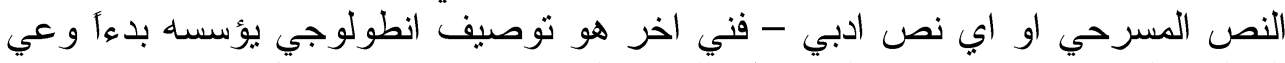

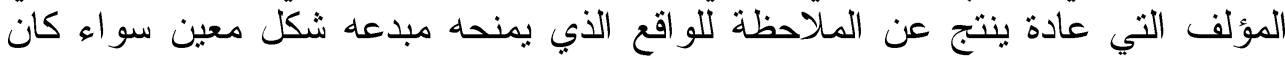

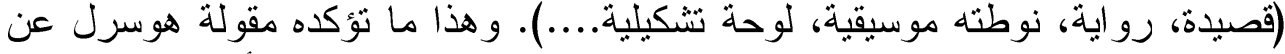

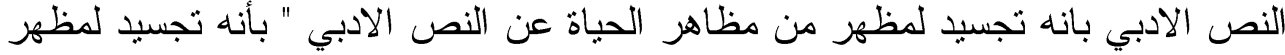

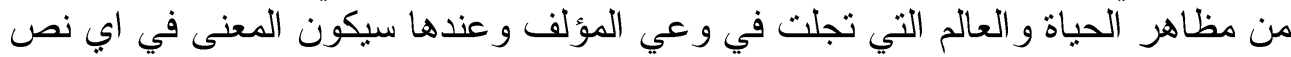

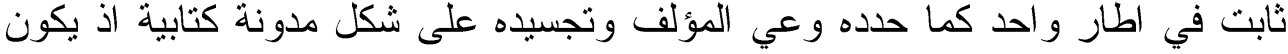

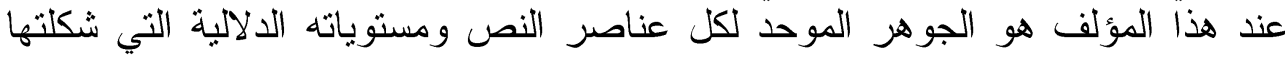

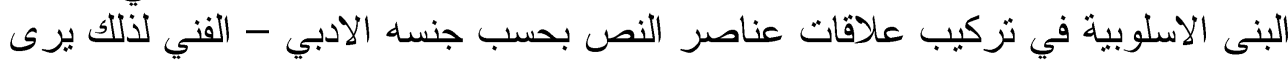

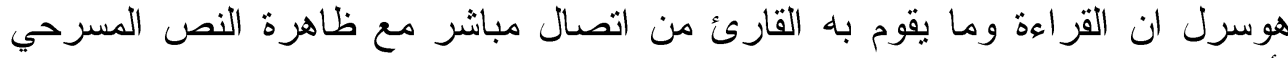

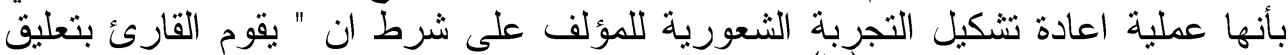
كل احكامه وفرضياته اعادة السابقة" (10)

لأن القراءة (معرفة مؤجلة لخلق الصور الذهنية ونسعى دائما الى تحقيق تمثيل

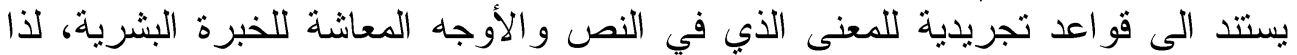

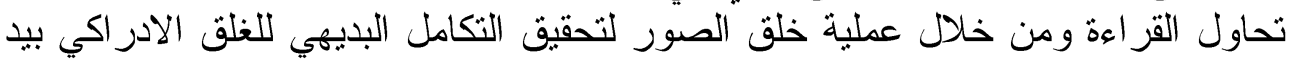

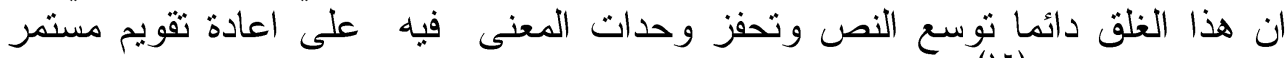

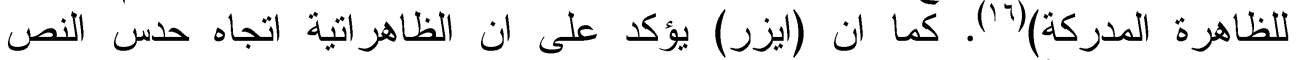

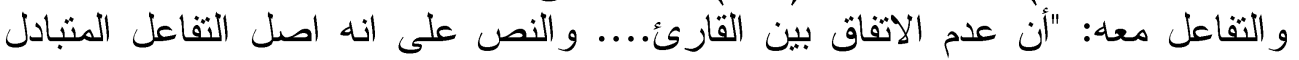

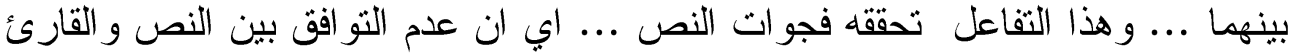

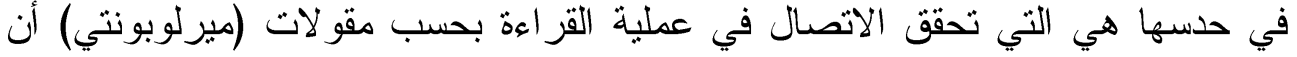

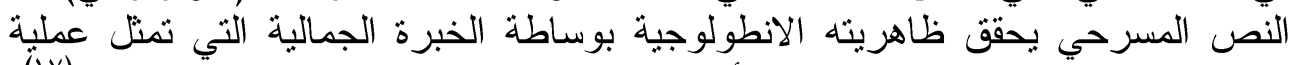

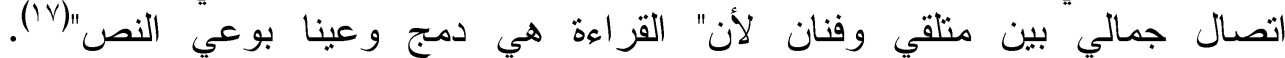
و الظاهز اتية تثقارب نقديا من هذه القر اعة لأنها تضم الفعل و البنية في اطار فكرة واحة واحدة

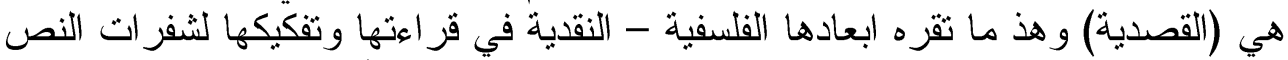

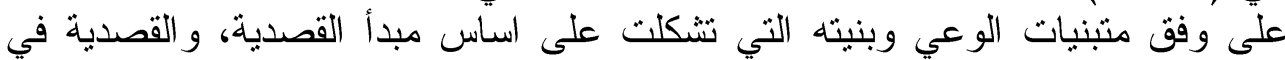
النص المسرحي هي تجسيد لشعور ومضامين ذات المؤلف في فكرة وبنية الفعل لجزئية

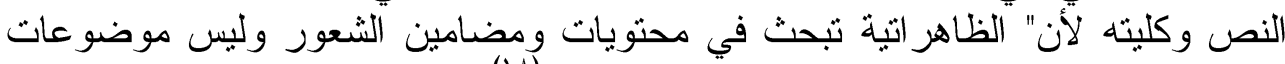

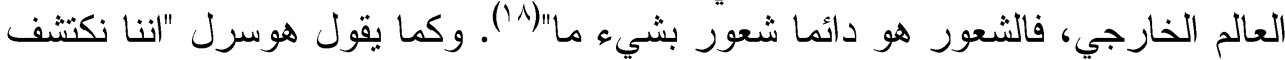

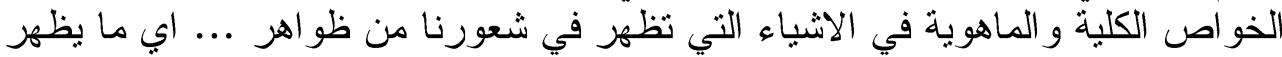


من الثيء و النص المسرحي هو رؤية قصدية لما رصد المؤلف من ظو اهر ومحاكاتها

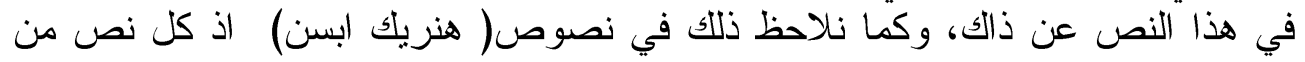

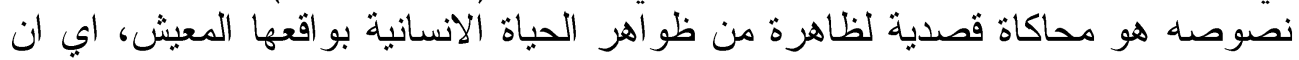

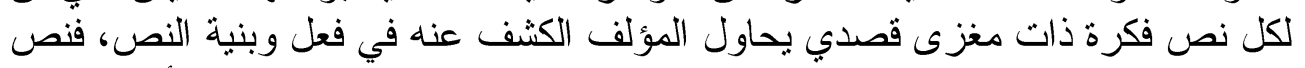

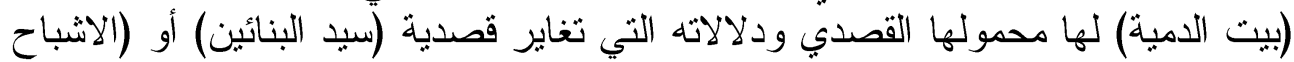

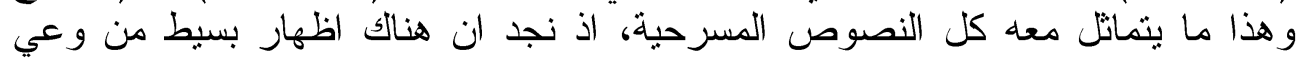

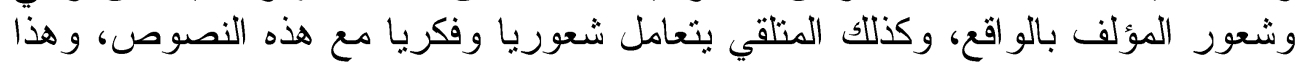

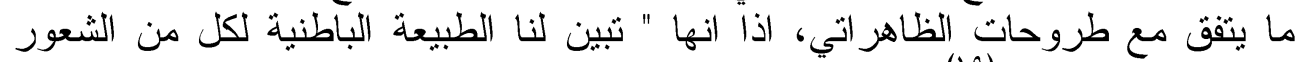

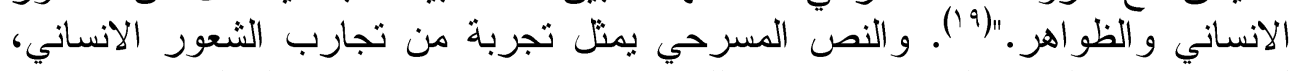

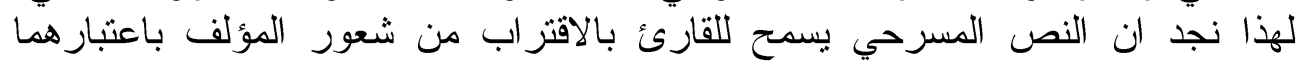

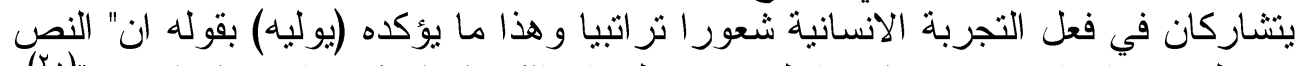

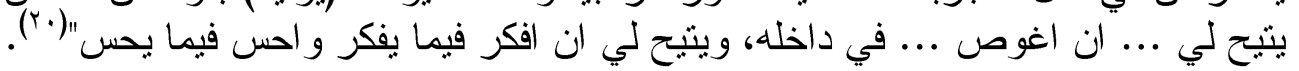

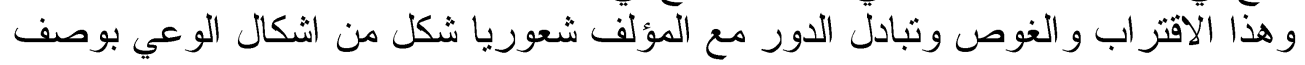

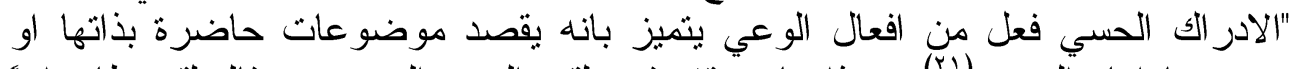

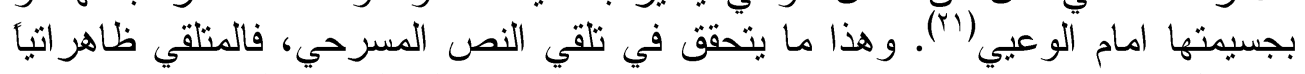

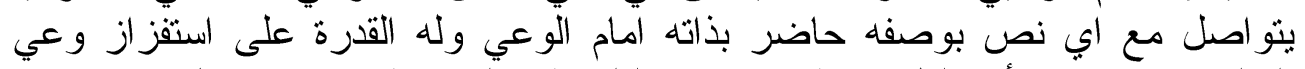

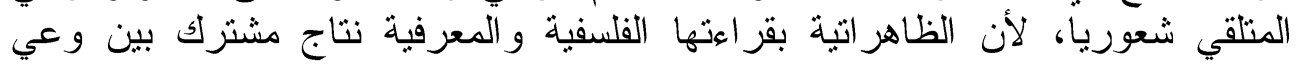

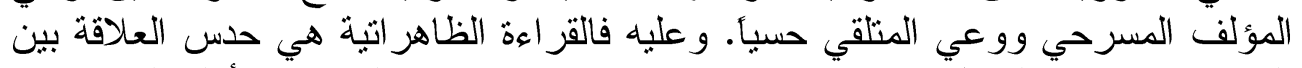

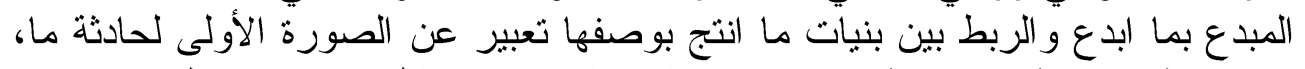

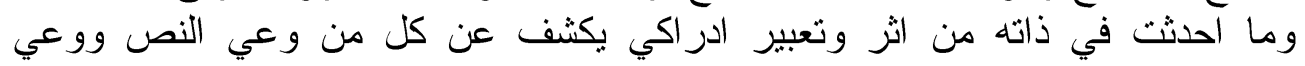

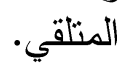

ثالثاً: التتأويل الظاهر اتي للنص المسرحي:

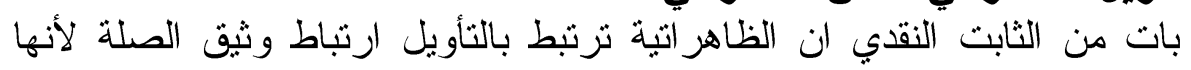

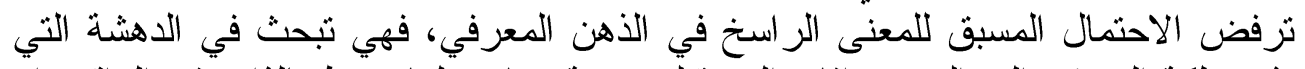

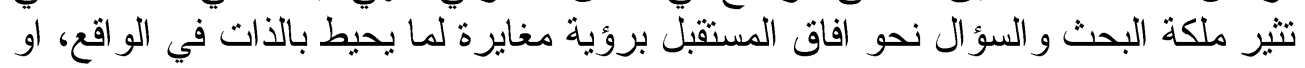

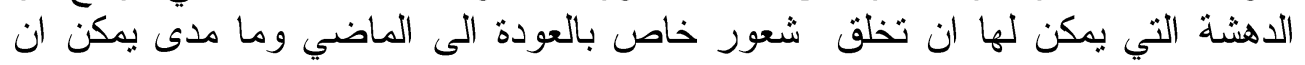

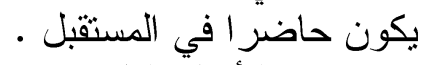

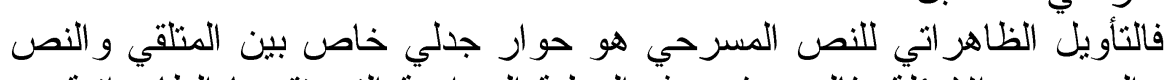

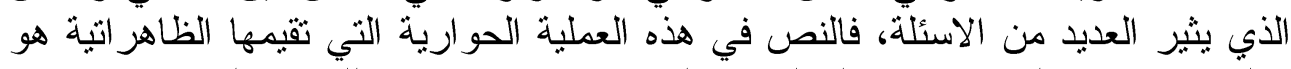

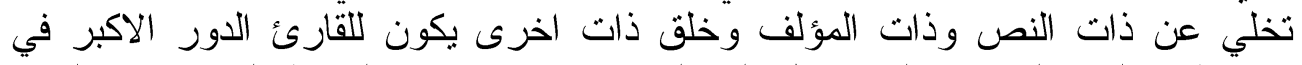

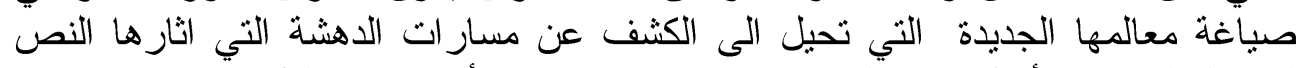

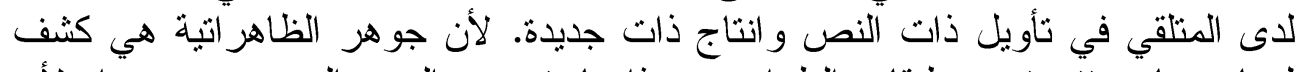

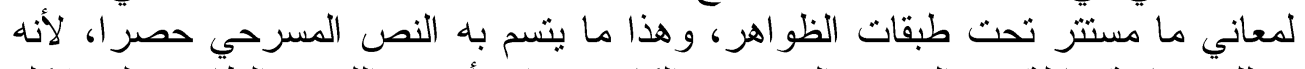

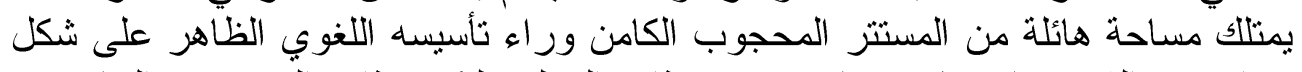

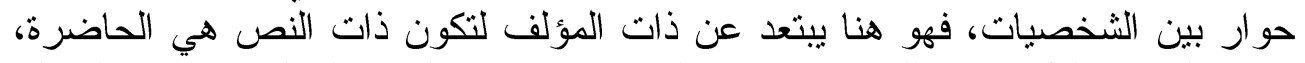

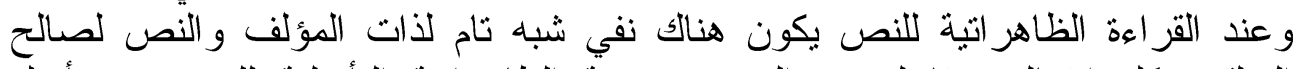

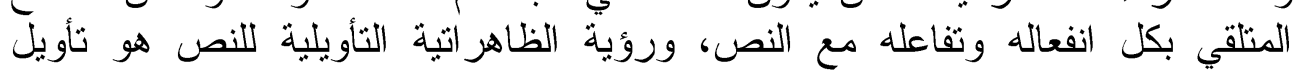

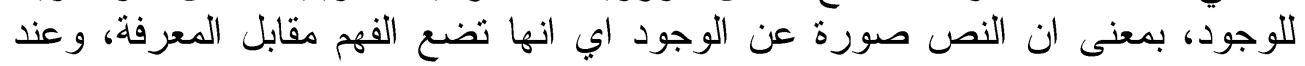

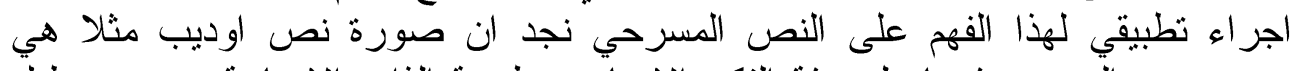
صورة عن الَّجود وفضاء لمعرفة الفكر الانساني وطبيعة الذات الانسانية. ونص عطيل 
وتاجر البندقية صورة عن ظاهرة الو اقع العنصري وضغطها على الانسان المقذوف في

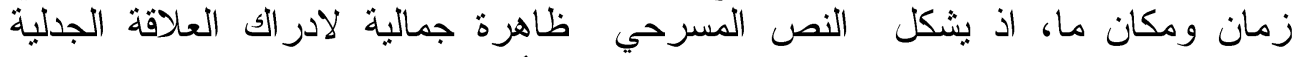
لكينونة الانسان الوجودية التي تمثل منحى ظاهي الهر اتي تأويلي.

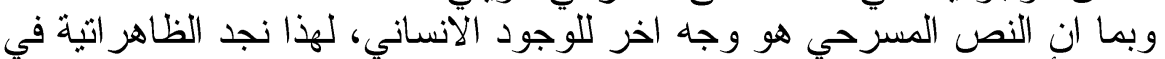

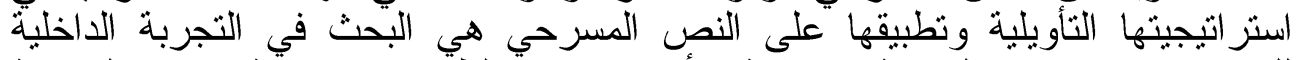

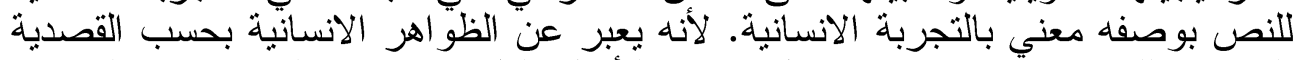

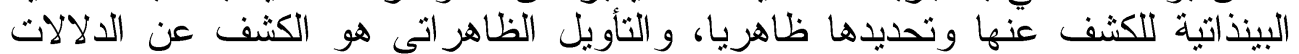

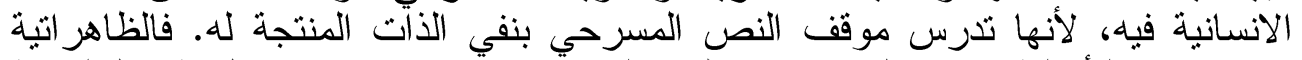

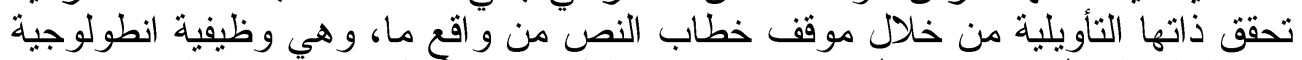

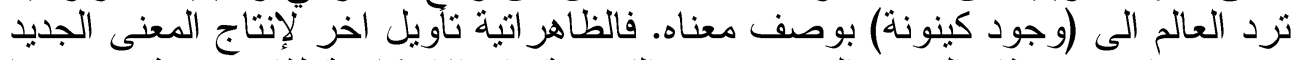

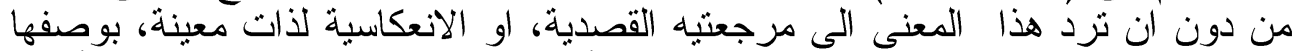

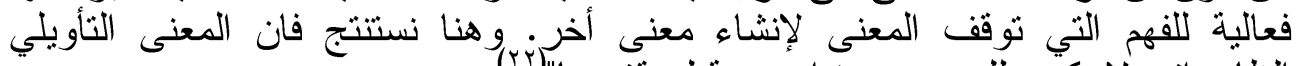

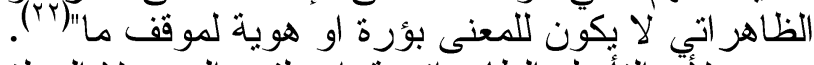

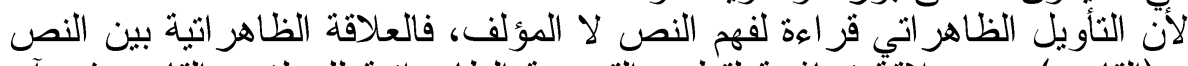

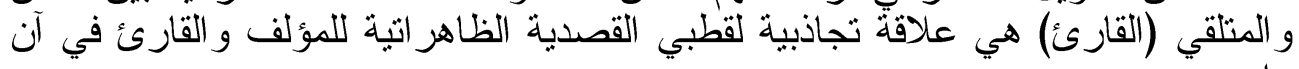

\section{المحور الاجر ائي}

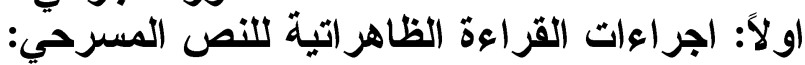

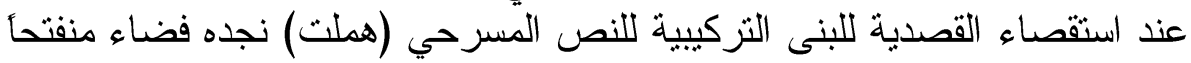

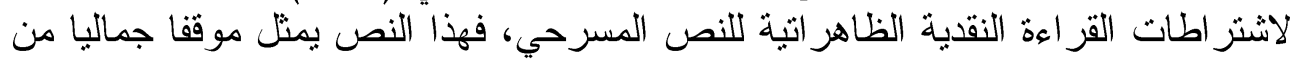

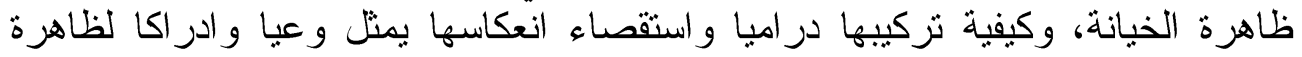

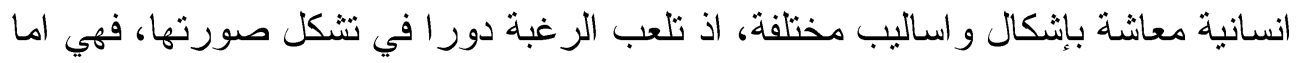

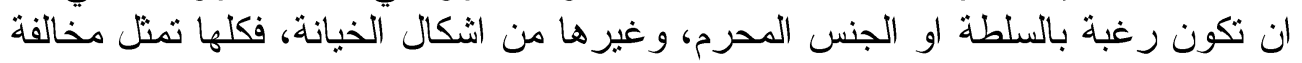

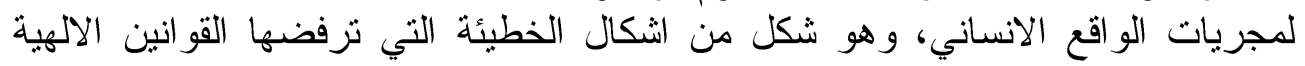

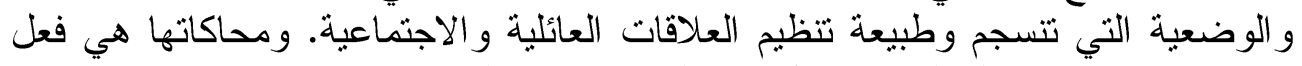

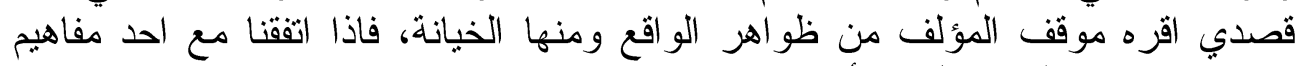

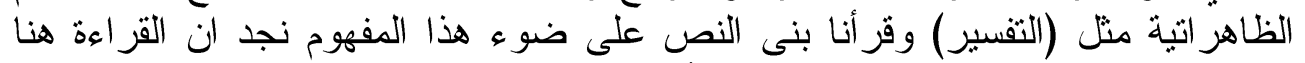

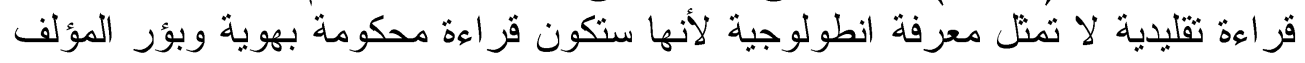

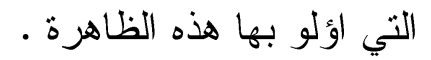

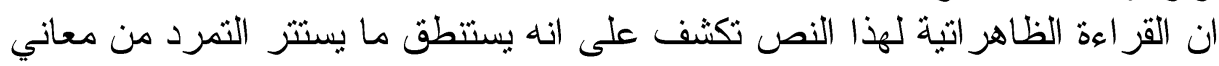

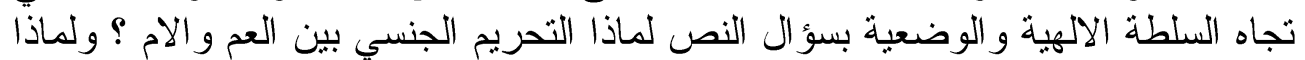

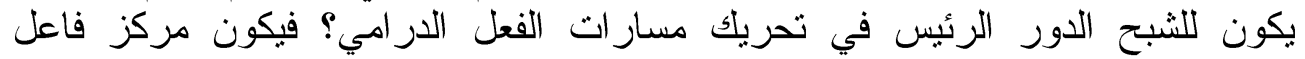

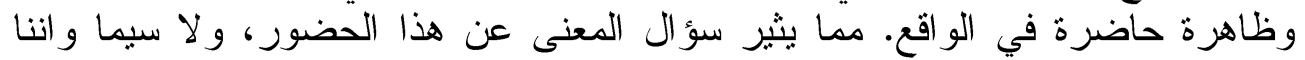

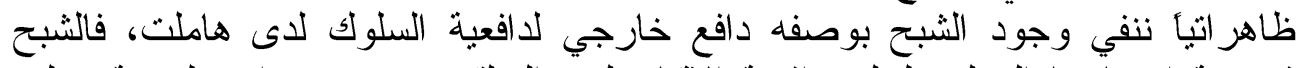

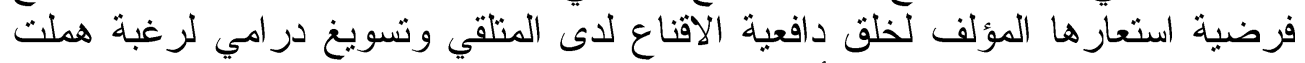

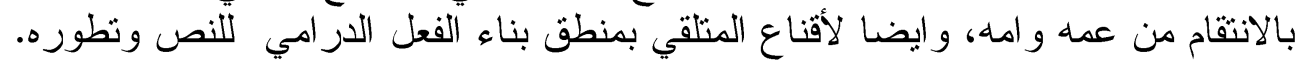

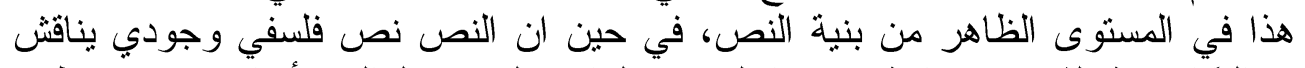

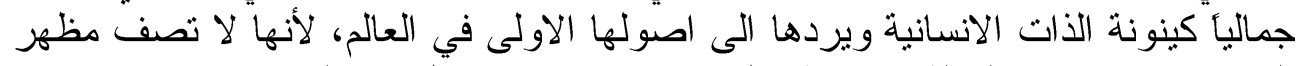

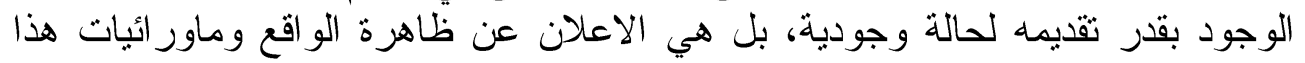

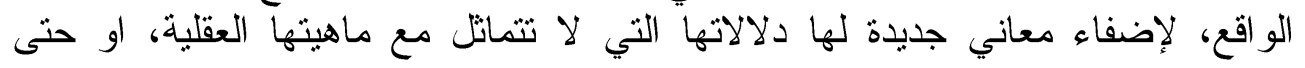


التعبيرية ضمن سياق المنطق الواقعي، بل نه افترض لها ماهية جديدة هي (فرضية

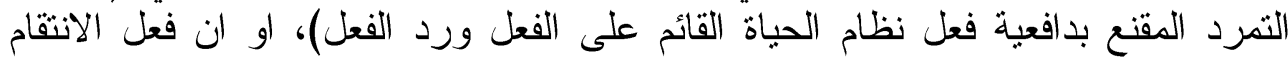

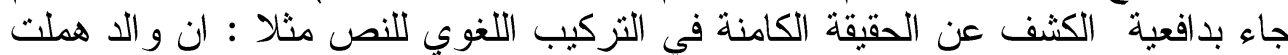

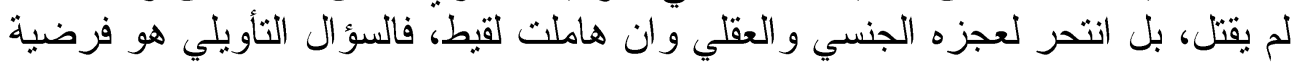

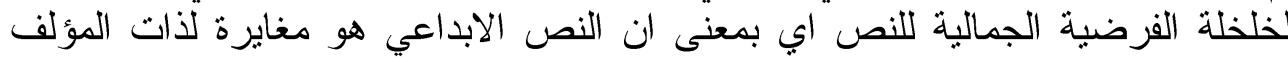

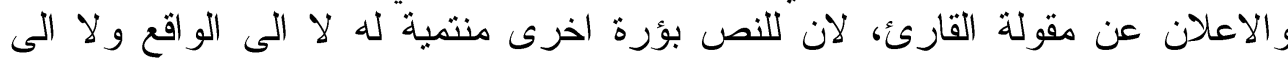

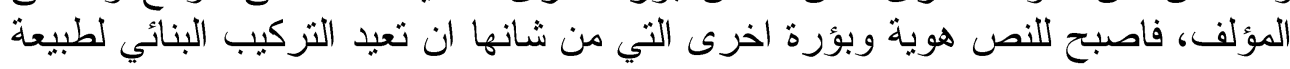

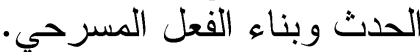

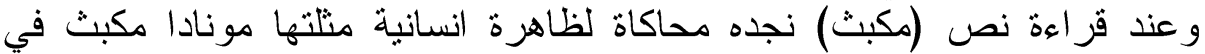

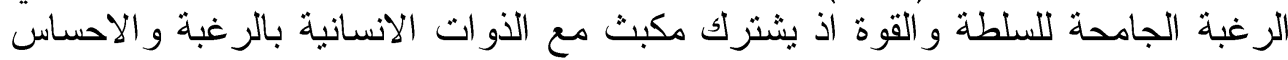

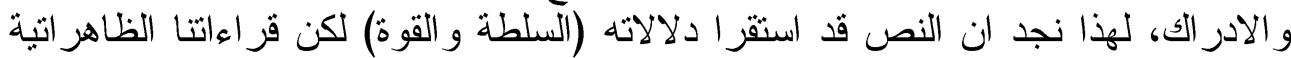

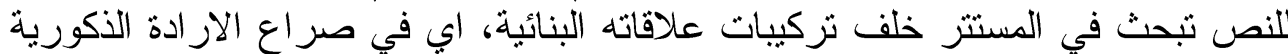

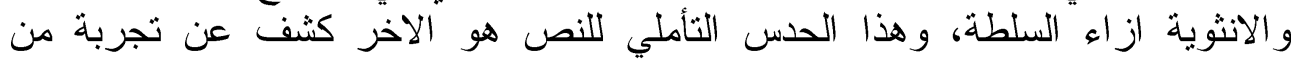

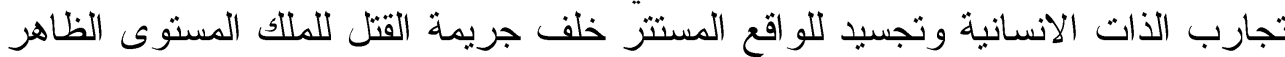

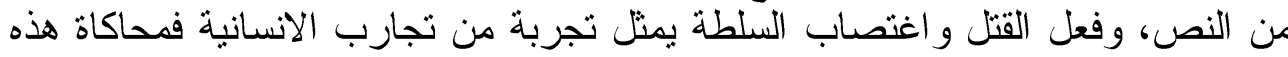

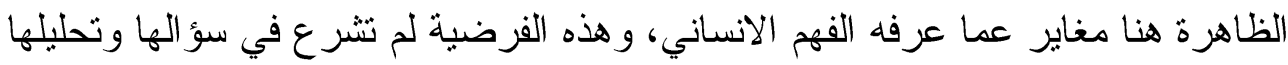

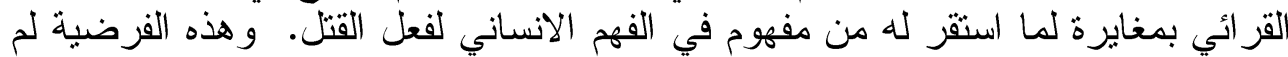
تتطلق من المقو لات اللغوية، لأننا عند تأمل الظاهرة المسرحية مكبث ظاهر اتبأ نجد سلطة

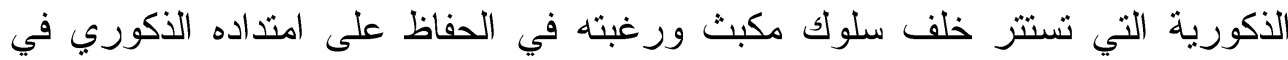

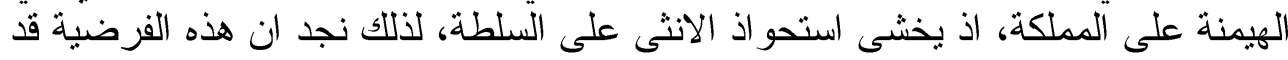

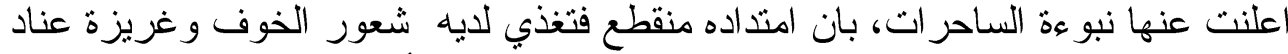

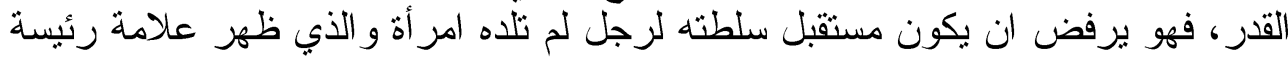

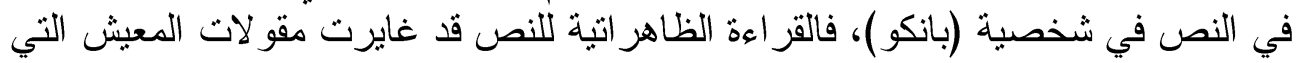

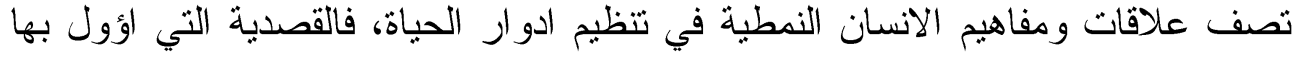

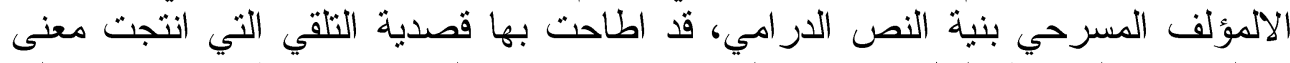

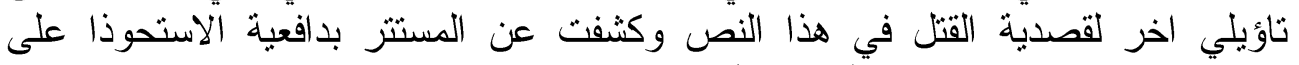

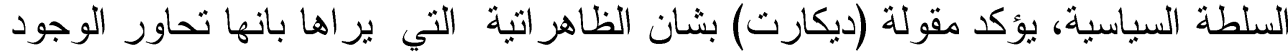

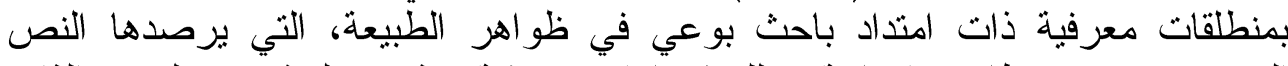

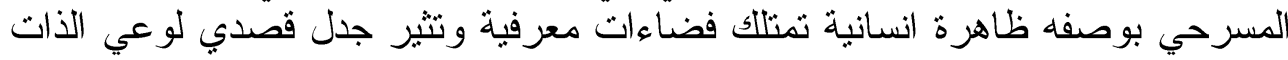

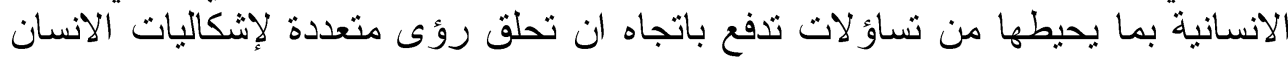

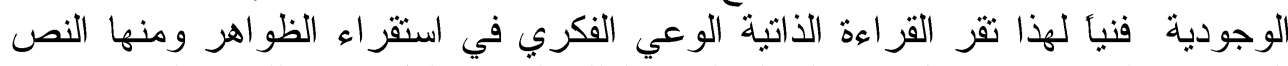

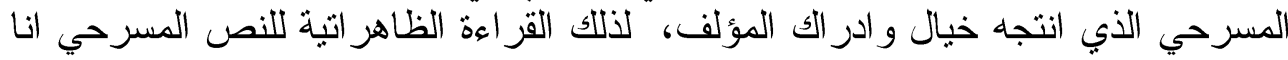

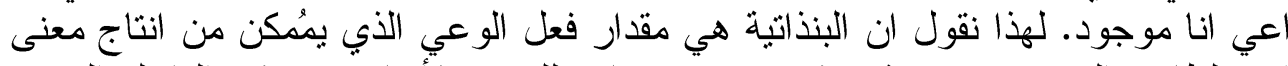

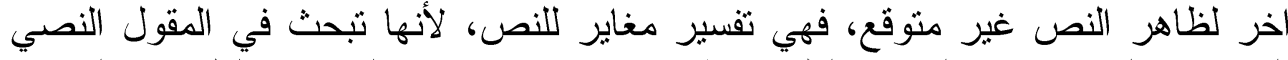

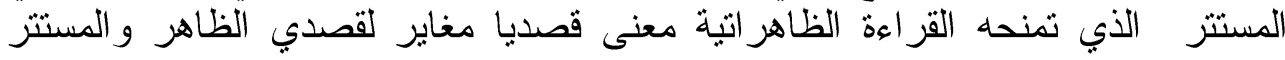

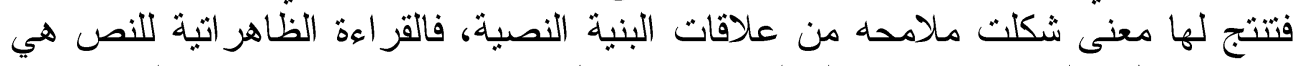

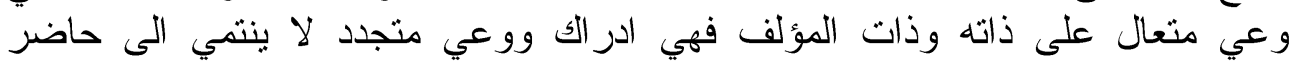

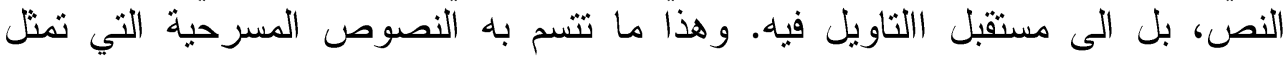

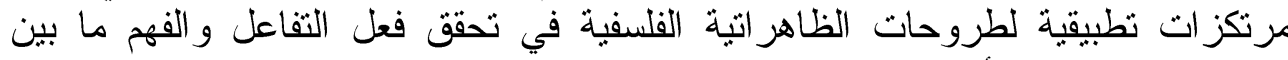
النص و التلقي لينتج تأويل يحدس النص بشكل مغاير 


\section{النتائتج}

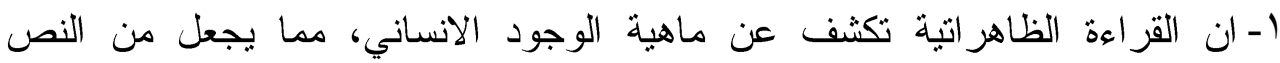

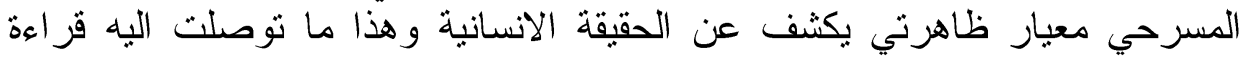

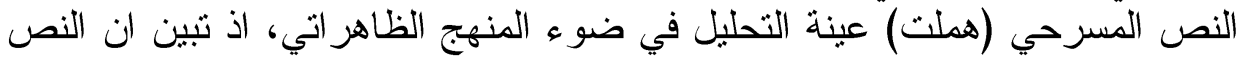

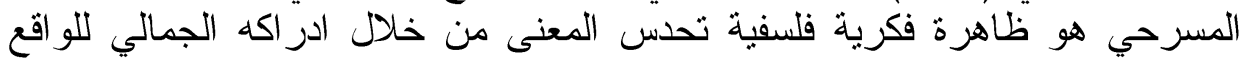

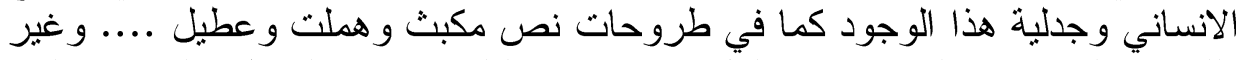

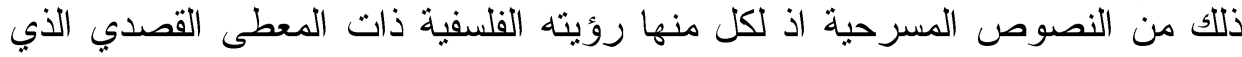

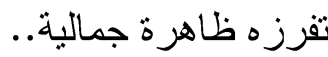
r- ان النص المسرحي يكشف عن قصديته الجمالية التي لها هدف ذو معنى مؤسس من

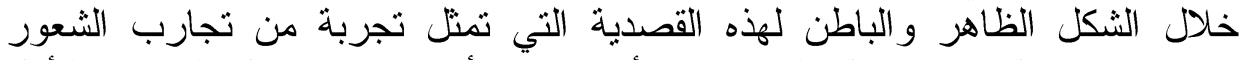

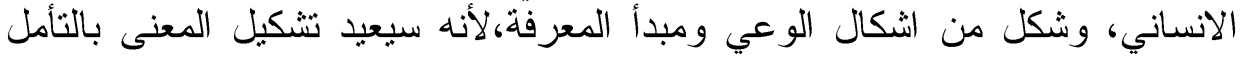

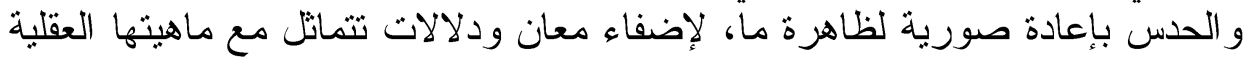

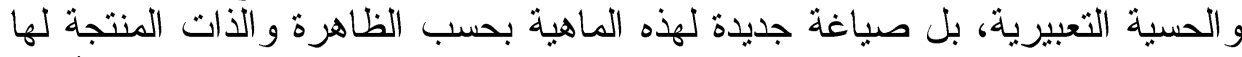

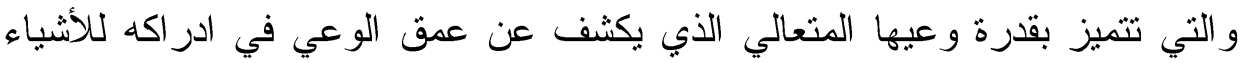

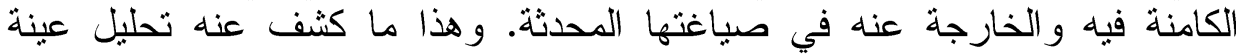
البحث بحسب استر اتيجية القرأهة الظاهر اتية للنص التي انزاحت باتجاه قصدية النص

حصر إنمان

r-كشفت القراءة الظاهر اتية للنص المسرحي بانه الفضاء التطبيقي الامثل لطروحات

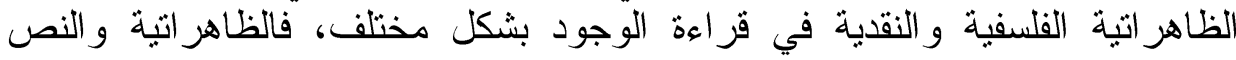

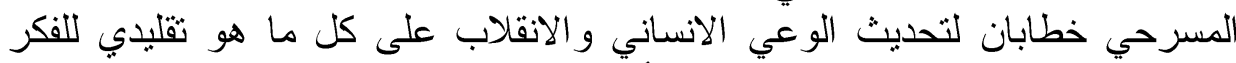

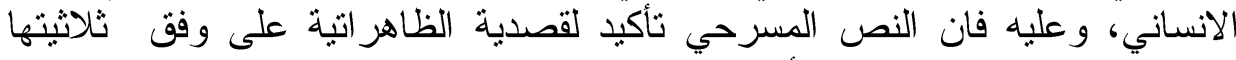

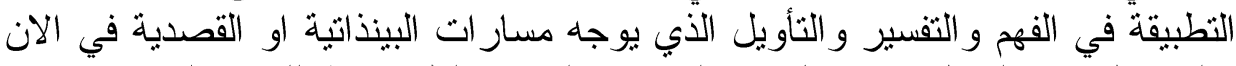

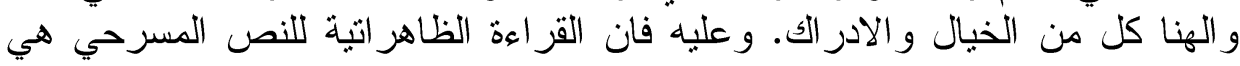
كثف عن حقيقة الوجود وكما يقول نيتشه في زمن التلقي وسياق النص الذاني الذي العلن عنه حضور ا ظاهر اتيا ع- تؤكد الظاهر اتية على رفضها لأي حكم جمالي استباقي لأنه سيضع النص في في ضوء

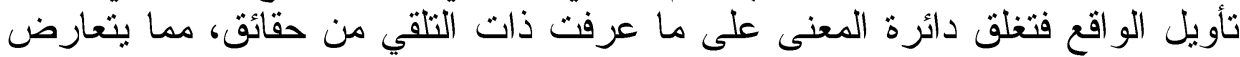

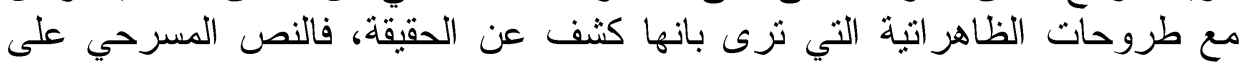

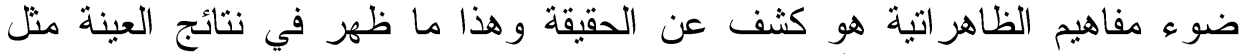

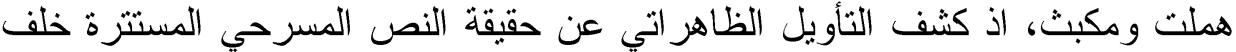

\section{| - الاستنتاجات} مقو لاته و هذا ما ظهر في عينة البحث

1-الظاهر اتية حس لظاهرة النص من وعي معاكس لوعي النص لذلاتك هي وعي متعال

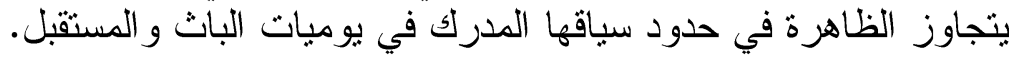

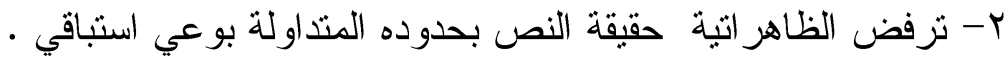

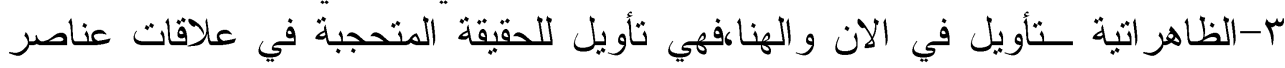
النص جماليا 


\section{Abstract \\ The apparent reading of the theatrical text \\ By Safra Naji Jassim}

The phenomenon draws its philosophical data according to Thesis (Husserle) by reconciling thought with the world by describing the higher structures of human consciousness, and that is why phenotype found a knowledge space that would be a science of consciousness|, and can describe the effect The exchange between the self and the world, and this philosophical saying that Husserle worked on in contemporary thought that finds its resonance in the theatrical text as a phenomenon that concerns the processes of thinking, awareness, understanding and human experience, it is one of the spaces of this conscious thought of human reality, because it works to The inner self of human consciousness is brought to the fort été by presenting a hidden mental act in the reading phenomenon in the theatrical text.

In order to monitor this conscious interconnection between the text and the phenomena in reading human thought with transcendental awareness, we worked to ensure that this monitoring is through three axes: the first represents the systematic axis that includes the problem of research and the importance of research and the purpose of research, and the second axis is the theoretical foundation, which included three entries:

First: a conceptual introduction to phenomena

Second: The foundations of monetary phenomena

Third: The apparent interpretation of the theatrical text

The third axis is to deal with the procedures of the apparent reading of the theatrical text

The research was concluded with its findings and the list of research sources, and the most important findings are:

1- The phenomenological reading reveals what human existence is and this is what characterizes the theatrical text as a phenomenon, and this is what appeared when reading the text in the light of the phenomenological approach, as it turns out that the theatrical text establishes a philosophical vision that attempts to intuition the meaning through its aesthetic understanding of human reality and the dialectic of this existence, as in the thesis of a macbeth, hemelt, a tatel and other texts, since each text has its own philosophical vision with intent.

2- The analysis of the research sample showed that the theatrical text is the space that reveals the presence and represents the phenotypes, philosophical and critical thesis in which the reading of existence is presented outwardly, in the form of both phenomenology and theatrical text two speeches to modernize human consciousness and the reversal of all that is traditional and stereotypical in human thought. The theatrical text is therefore a transcendent consciousness and an affirmation of the intention of the phenomena, which reveal the truth of existence, as Nietzsche says. 


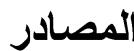

1-سلدن، رامان: النظرية الادبية، ت: سعيد الغانمي، المؤسسة العربية للدراسات و النشر، بيروت، طا،

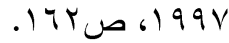

r-بوزيان، دليل محمد واخرون: اللفة والمعنى مقاربات في فلسفة اللفة، تقيم مخلوف سيد احمد،

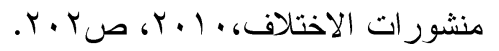

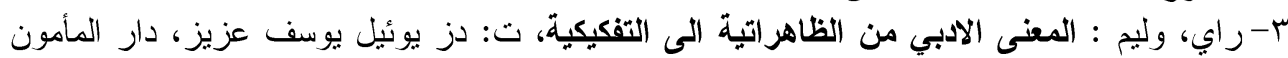

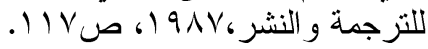

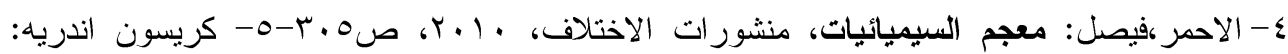

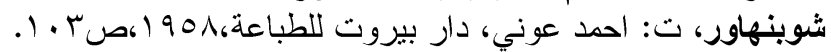

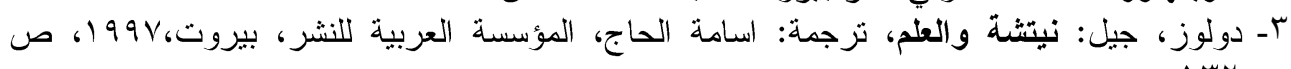

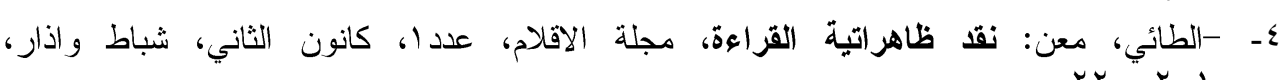

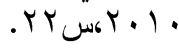

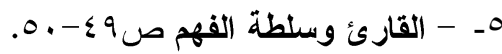

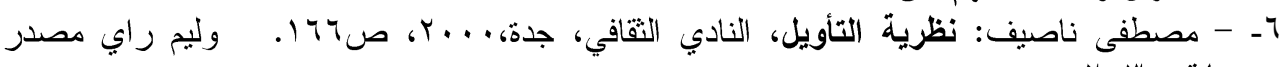

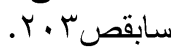

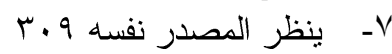

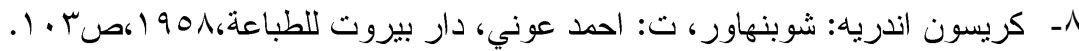

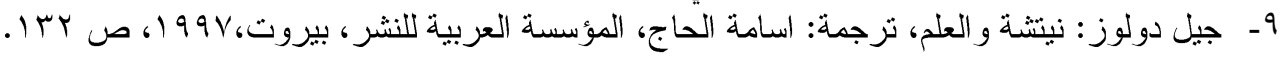

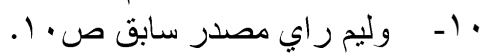

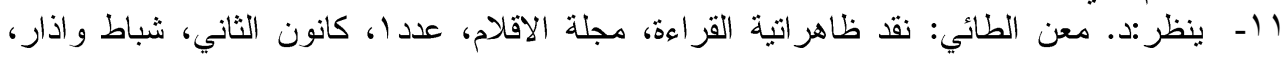

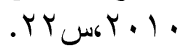

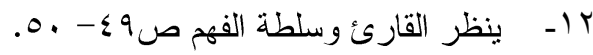

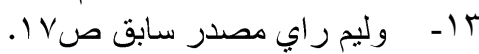

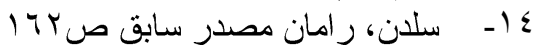

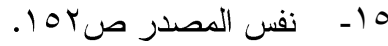

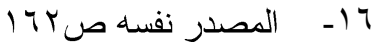
IV

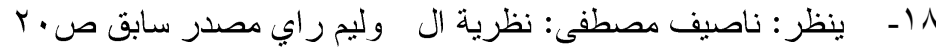

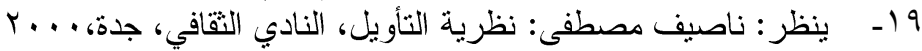

